\title{
The impact of adult child emigration on the mental health of older parents
}

\author{
Irene Mosca $^{1}$ • Alan Barrett Bl,2,3 $^{1,2}$
}

Received: 28 May 2014 / Accepted: 3 December 2015 /

Published online: 16 January 2016

(C) Springer-Verlag Berlin Heidelberg 2016

\begin{abstract}
We explore whether older parents of adult children who emigrate experience, in the short term, increases in depressive symptoms and loneliness feelings compared to parents whose children do not migrate. We use data from the first two waves of The Irish Longitudinal Study on Ageing, which is a nationally representative sample of 8500 people aged 50+ living in Ireland. To deal with the endogeneity of migration, we apply fixed-effects estimation models and control for a broad range of life events occurring between the two waves. These include the emigration of a child but also events such as bereavement, onset of disease, retirement and unemployment. We find that depressive symptoms and loneliness feelings increase among the parents of migrant children but that the effect is only present for mothers. As the economic burden of mental health problems is high, our findings have potentially significant impacts for migrant-sending regions and countries.
\end{abstract}

Keywords Emigration · Depression · Mental health · Older parents

JEL Classification $\mathrm{I} 15 \cdot \mathrm{J} 14 \cdot \mathrm{F} 22$

Responsible editor: Klaus F. Zimmermann

Irene Mosca

moscai@tcd.ie

1 The Irish Longitudinal Study on Ageing, Trinity College Dublin, Dublin 2, Ireland

2 Economic and Social Research Institute, Dublin 2, Ireland

3 Institute for the Study of Labor (IZA), Bonn, Germany 


\section{Introduction}

The impact of emigration on sending countries has received increasing attention in recent years. Among the issues that have been explored are the potentially positive effects of remittances and the potentially negative effects of the so-called brain drain. These are enormously important issues because they impact directly on the capacity of less-developed countries to generate economic growth and reductions in poverty.

One strand of the literature on sending countries has looked within families and has investigated how family members left behind are affected by the emigration of parents, children and spouses. On the emigration of parents, Cox-Edwards and Ureta (2003) showed that this had a positive impact on the education levels of the children left behind in El Salvador. However, Giannelli and Mangiavacchi (2010) found the opposite results for Albania. Also, McKenzie and Rapoport (2011) found that living in a migrant household in rural Mexico had a negative effect on schooling attainment and attendance. Mu and de Brauw (2015) and McKenzie and Hildebrandt (2005) found positive effects of parental emigration on children's health in China and Mexico, respectively. As regards the emigration of spouses, Grigorian and Melkonyan (2011) found that the emigration of a spouse tended to reduce the labour supply of the spouse left behind.

In this paper, we explore the short-term impact of adult child emigration on the mental health of older parents and in so doing we build on the work of Antman (2010, 2011 and 2013). Using the first wave of the Mexican Health and Ageing Study (MHAS) and addressing endogeneity problems by using instrumental variables methods, Antman found evidence of negative impacts on both the mental and physical health of Mexican parents due to the emigration of their children. As Antman (2010, p. 208) argues, these are important findings because they 'cast further doubt on the assumption that family members left behind in source countries should always benefit from the international migration of their relatives'.

We use data from the first two waves of The Irish Longitudinal Study on Ageing (TILDA). This is a nationally representative sample of people aged 50 and over and living in Ireland, with wave 1 undertaken in 2009-2011 and wave 2 undertaken in 2012-2013. Given the economic collapse in Ireland in 2008 and 2009, high levels of outmigration have resumed and so Ireland once again provides a useful setting in which to study emigration. The TILDA data contain information on whether the children of the respondents live in Ireland or in another country. Combining the data from wave 1 and wave 2, we can identify the parents whose children emigrated between the waves. The data also contain measures of mental health at wave 1 and at wave 2 . Hence, we can observe changes in mental health. Through fixed-effects models, we explore whether, in the short term, there is a relationship between the emigration of children and the mental health of parents, controlling for other negative life events that occurred between waves 1 and 2. Antman (2010, 2011, 2013) had to rule out the use of parental fixed effects as there was little variation in the migration of adult Mexican children between the first two waves of MHAS. As variation in the migration of adult children in the TILDA data is considerably larger, we make an important addition to Antman's earlier work. 
Our main analysis is restricted to a homogeneous group of parents, which is parents all of whose children were living in Ireland at wave 1 . We exploit the exogeneity of the migration impetus that occurred between the two survey waves and compare the changes in mental health experienced by parents who saw a child emigrating between the two waves to those of parents all of whose children were still living in Ireland at wave 2. We find evidence of increased levels of depressive symptoms and feelings of loneliness among the mothers of emigrants but not for fathers.

It is worth noting that the TILDA data do not include information on remittances, but this is not a concern. For studies that are conducted in developing countries, the inclusion of remittances in the analysis would be important because it is likely that remittances would have an ameliorating influence on any negative mental health effects experienced by family members left behind. In Ireland, the social security system is such that there would be little need for remittances and such payments never appear in surveys of income or wealth. In addition, a number of research papers (for example, see Barrett and O'Sullivan 2014) have shown how older people were somewhat insulated from the effects of the recession, due in part from the omission of old-age pensions from the list of social welfare payments that were cut in an effort to restore balance to the public finances. This lack of importance of remittances in Ireland means that the estimates which we produce of the impact of child emigration on parental mental health will be more pure, when compared to situations in developing countries where the effects of emigration might be partly obscured by the effect of remittances.

The paper is structured as follows. In Section 2, we describe the data more fully. In Section 3, we set out our estimation framework and discuss how our fixed-effects approach is designed to overcome the key empirical challenge in studies such as this, namely the endogeneity of the migration decision. In Section 4 , we first investigate associations between child migration and parental mental health and then present the results of our fixed-effects models. We also discuss additional efforts to rule out endogeneity as the driver of our results. We conclude in Section 5.

\section{The data}

The data we use are from the first two waves of The Irish Longitudinal Study on Ageing. TILDA is a nationally representative sample of community-dwelling individuals aged 50 and over (and their spouses and partners of any age) living in Ireland. It is modelled closely on the Health and Retirement Study (HRS), the English Longitudinal Study on Ageing (ELSA) and the Survey of Health, Retirement and Ageing in Europe (SHARE).

The first wave of data was collected between October 2009 and July 2011. A total of 8504 participants were recruited from a clustered random sample of all households in Ireland. All participants provided written informed consent. Those with cognitive impairment that prevented consent being given were not included in the study. Respondents first completed a computer-assisted personal interview (CAPI) in their own homes. Respondents were then invited to travel to one of two health centres for a comprehensive health assessment. If unable or unwilling to attend a health centre, 
they were offered a modified and partial assessment in their own home. Respondents were also asked to complete a self-completion questionnaire (SCQ), which was designed to explore areas that were considered particularly sensitive, such as relationship quality, loneliness and stressful life events. A total of 6910 respondents aged 50 and over completed and returned the self-completion questionnaire. The overall response rate for the first wave of the study was $62 \%$.

The second wave of data was collected between April 2012 and January 2013 and a response rate of $86 \%$ was achieved (Dooley 2014). Respondents completed a CAPI in their own homes and were asked to complete a SCQ. Unlike wave 1 of the study, there was no health assessment at wave 2 . While every effort was made to achieve in-person interviews, 80 proxy interviews were carried out for respondents who were deemed unable to participate in an interview due to a physical or cognitive impairment. Proxy interviews are excluded from our analyses, for the simple reason that we do not observe the relevant variables for these respondents. To account for the sampling structure at wave 1 and non-response at wave 2, we use appropriate survey estimation methods and weights that are available in the data.

Because our interest is in seeing if the outmigration of a child leads to a deterioration in parental mental health in the short term, we restrict the sample used in most of the fixed-effects models to parents of children aged 16 and over at wave 1 and all of whose children were living in Ireland at wave 1. We also exclude from the sample parents aged more than 75 as the probability of having an emigrating child drops significantly for parents in this age group. This gives a sample of 2523 parents. Of this group, 357 parents have seen one or more children emigrate between the two survey waves. A total of 306 parents have seen only one child emigrate, 48 parents have seen two children emigrate and three parents have seen three or four children emigrate. The parents in our final sample have, on average, 3.1 living children.

We focus on parents all of whose children were living in Ireland at wave 1 in an effort to get the cleanest possible view of the impacts of child emigration on mental health. To illustrate our reasoning with just one example, while we could include parents some of whose children had already emigrated, we do not know when these earlier emigration events occurred. Hence, we could be comparing parents whose children emigrated in the recent past or the very distant past. Nonetheless, and in the interest of completeness, in the Appendix, we re-estimate the core regression model but include additional parents who have been impacted upon by migration-(a) those who already had a child abroad at wave 1 and who saw another child emigrate between waves 1 and 2 and (b) those who saw a child return from abroad between waves 1 and 2. Results are presented in Table 14 and discussed in the Appendix.

Figure 1 presents data on emigration from Ireland in recent years. As can be seen, the pattern of emigration follows the economic cycle, thereby suggesting that economic motives dominate in migration decision-making in Ireland. The Irish economy suffered a period of stagnation in the 1980s, and this led to a spike in outward migration in the late 1980s. A strong economic recovery commenced in the early 1990s and endured through the early and mid-2000s, the so-called 'Celtic Tiger' period. These years of economic growth saw outward migration fall to historically low levels and also generated strong inflows. The economic crisis of the late 2000s was particularly acute in Ireland, with real GDP contracting by $10 \%$ between 2008 and 2010. As can 


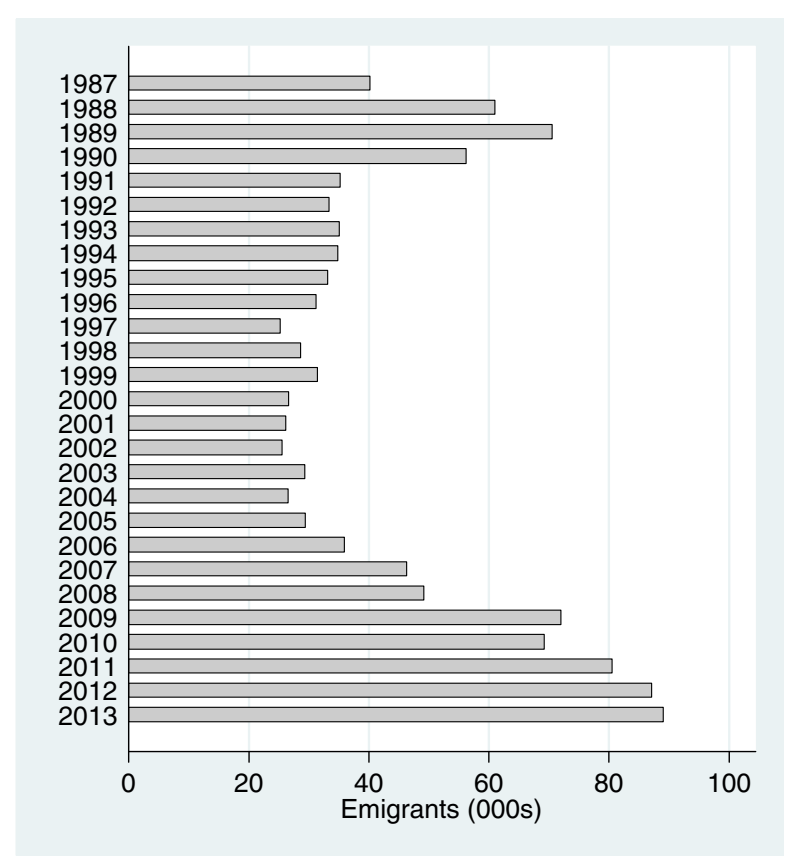

Fig. 1 Emigration from Ireland in thousands, 1987 to 2013. Source: Central Statistics Office (CSO)

be seen again in Fig. 1, this led to the re-emergence of large-scale outflows which exceeded the previous peak of the late 1980s.

Before proceeding to discuss the estimation framework, we will make three points with respect to our data. First, the TILDA data were collected from 2009 onwards and this is advantageous from the following perspective. Based on Fig. 1, it seems reasonable to argue that much of the emigration from Ireland in this period was the result of a shock which was exogenous for the families in the TILDA data. This is crucial to our analysis because it allows us to characterise Ireland's emigration experience of this period as a natural experiment of sorts with consequent implications for the interpretation of our results. Second, as discussed in Section 1, our data do not include information on remittances but we are not concerned about this. Unlike research on migration from developing countries where remittances are important, the existence of a European-type social security system in Ireland (including state pensions) means that remittances are not an important part of Ireland's modern-day emigration experience. Third, although we can identify in our data that a child of a TILDA respondent left Ireland between waves 1 and 2 of the survey, we do not have information on destination. We know from other data sources that the destinations of emigrants from Ireland were quite varied over the period in question. For example, of the 89,000 who left in 2013, almost 22,000 travelled the short distance to the UK; however, another 15,400 went to Australia. A comparison of results by destination would have been interesting but this is not possible. 


\section{The estimation framework}

Previous research has shown that the main non-genetic predictors of (poor) mental health in later life are gender, age, marital status, socioeconomic status, labour market status, physical health, functional limitations and familial and social circumstances (Beekman et al. 1995; Sonnenberg et al. 2000; Dykstra et al. 2005; Buber and Engelhardt 2008; Schoevers et al. 2000). Based on this, we express parental mental health as

$$
M H_{i t}=\alpha+\beta w_{t}+\gamma D_{i t}+\delta S E_{i t}+\lambda P H_{i t}+v E C_{i t}+\omega O C_{i t}+a_{i}+u_{i t} t=1,2
$$

where $M H_{i t}$ denotes the mental health status of parent $i$ in time period $t ; w$ is a dummy variable that equals zero when $t=1$ and one when $t=2 ; D$ is a vector of demographic variables; $S E$ is a vector of socioeconomic variables; $P H$ is a vector of physical health variables; $E C$ is the independent variable of most interest here, emigration of a child; $O C$ is a vector of other children's circumstances; $a_{i}$ is a timeinvariant unobserved effect and $u_{i t}$ is the time-varying error. Here, $a_{i}$ and $u_{i t}$ are unobserved, whereas $D_{i t}, S E_{i t}, P H_{i t}, E C_{i t}$ and $O C_{i t}$ are observed.

OLS estimation of Eq. 1 is complicated by the (potential) endogeneity of the explanatory variables employed as these may not be orthogonal to the residual term $a_{i}+u_{i t}$.

Focusing first on individual specific and time-invariant unobserved effects, we remove them by putting into operation fixed-effects models based on the first differences of Eq. 1 over time. Let $\Delta$ denote the first-difference operator from $t=1$ to $t=2$, so, for example, $\Delta D_{i}=D_{i 2}-D_{i 1}$. We have that

$$
\Delta M H_{i}=\beta+\gamma \Delta D_{i}+\delta \Delta S E_{i}+\lambda \Delta P H_{i}+v \Delta E C_{i}+\omega \Delta O C_{i}+\Delta u_{i}
$$

Critically, the unobserved effect $a_{i}$ does not appear in Eq. 2 because it has been differenced away. Similarly, time-invariant regressors have also been differenced away. All time-variant regressors remain in Eq. 2 and are expressed as changes between the two waves. The intercept in Eq. 2 is the change in intercept from $t=1$ to $t=2$. Equation 2 explicitly considers how demographic, socioeconomic and physical health changes and changes in children's conditions over time affect parental mental health changes over the same time period.

Turning then to time-varying unobserved effects, the fixed-effects results of Eq. 2 will still be biased if there are unobserved transitory shocks that affect mental health and affect or are affected by child migration or any of the other explanatory variables. To deal with this time-varying endogeneity concern, the shocks have to be included as explanatory variables. It is therefore important that we include as many time-varying determinants of mental health as possible. ${ }^{1}$

\footnotetext{
${ }^{1}$ To illustrate, the death of a spouse or the sudden onset of a disease for an older parent may have direct instantaneous effects on her mental health and on children's circumstances. A child who is about to emigrate might decide not to emigrate if a parent suddenly becomes ill or less independent to care for the older parent. Or, alternatively, a child who is unsure on whether to emigrate or not might suddenly decide to emigrate to avoid caring responsibilities. Hence, we control also for physical, demographic and economic changes although our main interest is in investigating the effect of the shock 'child migration'.
} 


\subsection{Dependent variables}

We use three different measures of mental health: depressive symptoms; self-rated emotional/mental health and loneliness feelings.

\subsubsection{Depressive symptoms}

In TILDA, the 20-item Center for Epidemiological Studies Depression Scale (CESD) is used to measure the degree to which respondents have experienced a wide variety of depressive symptoms in the week prior to the interview (Radloff 1977). The test includes questions on negative feelings (like having the blues, experiencing life as a failure, feeling lonely or sad, having crying spells), on positive thoughts (as being hopeful about the future, feeling happy, enjoying life), on somatic activity (like losing appetite, suffering from a restless sleep, talking less) and on social contacts (experiencing other persons as unfriendly). Each of the 20 items is measured on a four-point scale leading to a total score of 60 , with higher scores indicating higher depressive symptoms. A cutoff score of $\geq 16$ is used to determine clinically significant depressive symptoms (Radloff 1977).

In the fixed-effects models, changes in depressive symptoms are obtained by subtracting the CES-D score at wave 1 from the CES-D score at wave 2. Positive changes indicate that depressive symptoms have increased between the two interviews. Negative changes indicate that depressive symptoms have decreased. Changes are then standardised so that they have a mean of zero and a standard deviation of one.

\subsubsection{Self-rated mental health}

In both waves, respondents are asked whether they rate their mental/emotional health as: excellent, very good, good, fair, or poor. The responses are then coded from 1 to 5 , with 1 being excellent and 5 being poor.

\subsubsection{Loneliness}

In TILDA, loneliness is measured using a modified version of the University of California Los Angeles (UCLA) Loneliness Scale (Russell 1996). Four negatively worded and one positively worded question are used: How often do you feel a lack of companionship? How often do you feel left out? How often do you feel isolated from others? How often do you feel lonely? How often do you feel in tune with the people around you? The frequency of the outcome variable is assessed as 'Hardly ever or never', 'Some of the time' or 'Often'. The responses to the five questions are summed and the final score ranges from 0 (not lonely) to 10 (extremely lonely).

As with depressive symptoms and self-rated mental health, changes in loneliness feelings are obtained by subtracting the loneliness score at wave 1 from the loneliness score at wave 2. Positive (negative) changes indicate that loneliness feelings have increased (decreased) between the two interviews. As with the other two dependent variables, we standardise the changes. Finally, because loneliness feelings are 
measured in the self-completed questionnaire in TILDA, the loneliness model is based on a smaller sample size as compared to the other two models.

\subsection{Independent variables}

\subsubsection{Child emigration}

The main independent variable of interest is whether or not a child of the parents in question emigrated. Previous research has shown that contact and emotional cohesion with children are associated with parental mental health. For example, Buber and Engelhardt (2008) found that older European parents who saw or talked to their child(ren) less often than once a week had significantly higher levels of depression. Silverstein et al. (2006) found that stronger emotional cohesion with children was associated with greater well-being among older Chinese parents. Dykstra and de Jong Gierveld (2004) found that among older Dutch women emotional loneliness was inversely related to weekly contact with children. Although child emigration per se does not imply that the relationship between children and parents will change, one can expect that it will pose a number of challenges on its quality and intensity.

In each wave of TILDA, respondents are asked a set of questions about their children, including whether they live with their parents, elsewhere in Ireland or outside of Ireland. We select our sample to be parents aged less than 76 whose children were all living in Ireland at wave 1 . If we observe in the wave 2 data that a child now lives outside of Ireland, this parent is coded as having seen a child emigrate. The fact that the observations on where the children live are contemporaneous with the other data collected at wave 1 and wave 2 provides an advantage over migration data that is recall biased. As noted in Section 2, although we know that children are living outside of Ireland, we do not have information on what country they are living in.

In the analyses of Section 3, the child emigration variable is expressed either as a dummy ( 1 if one or more children emigrated between the two survey waves and 0 otherwise) or as a proportion. To illustrate, we code the proportion variable as $50 \%$ if a parent had two children and only one emigrated. Similarly, we code it as $100 \%$ if a parent had one child and this child emigrated or if a parent had two children and they both emigrated.

\subsubsection{Demographic and socioeconomic changes}

The demographic events included in our model are widowhood and loss of close friends and relatives. The death of the spouse and the loss of close friends or relatives have regularly been shown as important sources of psychological stress (Choi and Bohman 2007; Dykstra et al. 2005; Theeke 2009).

Because changes in labour market status and changes in income may also affect mental health (Lindeboom et al. 2002; Dave et al. 2008; Mandal and Roe 2008; Tiedt 2013), we include retirement and becoming unemployed as regressors and also control for changes in weekly individual gross income. In TILDA, information on individual income is collected through a series of questions covering labour income and income from social welfare, pensions, investment incomes and other 
sources (O'Sullivan et al. 2014). The questions are taken directly from the recent versions of the European Union Statistics on Income and Living Conditions (EU-SILC) questionnaire. ${ }^{2}$ It is important to control for these changes so that we reduce the probability that 'child emigration' is simply a proxy for the effect of Ireland's economic recession on the parent in question.

\subsubsection{Physical health changes}

The evidence collected in the medical literature shows that disability, new medical illness and poor (self-perceived) health are significant risk factors for depression and mental health difficulties (Cole and Dendukuri 2003; Choi and Bohman 2007; Schoevers et al. 2000). Because TILDA includes a wide battery of questions on health status, we are in the fortunate position to observe and measure the extent to which the health status of TILDA respondents has changed or deteriorated between the two survey interviews.

Focusing first on the onset of disease, respondents are asked whether since the last interview they have been diagnosed with one or more cardiovascular conditions or chronic illnesses. Examples of cardiovascular conditions are high blood pressure, high cholesterol, heart attack or stroke. Examples of chronic illnesses are asthma, arthritis, osteoporosis or cancer. Onset of cardiovascular disorder and onset of chronic illness are included as regressors.

For the purpose of assessing functional capacity, respondents are asked about any difficulties they have in carrying out a range of activities. These activities fall into two groups: activities of daily living (ADLs), which are the basic tasks of everyday life, such as eating, bathing, dressing, toileting and moving about and instrumental activities of daily living (IADLs), which are the activities performed in order to live independently in a community setting, such as managing money, shopping, using the telephone, housekeeping, preparing meals and taking medications correctly. In our model, loss of functional capacity is measured by an increase in the number of ADLs and IADLs respondents have difficulties with.

Finally, we include two variables capturing whether respondents perceive that their physical health has deteriorated between the two survey waves. Self-rated physical health is measured using five response options: "excellent, very good, good, fair or

\footnotetext{
${ }^{2}$ Labour income consists of employee income from the respondent's main job in the past 12 months and the gross profit from self-employment for self-employed people as well as pre-tax farm income for those engaged in farming. Pension income is made up of both regular and lump sum income from occupational and private schemes. Social welfare payments made to the respondent, income from assets and irregular income are also included in our measure of gross income. To reduce item non-response in relation to income sources, unfolding brackets are used when respondents refuse or say that they 'do not know' the relevant amount. If respondents do not provide a point estimate and also do not provide a banded a value, we use hot-deck imputation techniques to impute the relevant amount. We use the hotdeckvar algorithm in STATA 12 (Schonlau 2005) and replace missing values with values randomly selected from donor observations. TILDA also includes a single comprehensive question about net household income. Unfortunately, because the phrasing of the question differs between the two waves, we cannot control for changes in household income in our model.
} 
poor'. We classify respondents by whether they have experienced a deterioration of one or two or more points in their physical health. To illustrate, a respondent who rates her physical health as very good in wave 1 and good in wave 2 would experience a one-point deterioration. A respondent who rates her physical health as very good in wave 1 and fair in wave 2 would experience a two-point deterioration.

\subsubsection{Changes in children's conditions}

Turning then to changes in children's conditions, other than emigration, we include two dummy variables capturing whether respondents have seen one or more of their children (a) become unemployed or (b) become widowed, separated, divorced or single between the two waves of the survey. As with the emigration variable, these variables are constructed by looking at the responses in both waves and by coding as 1 changes in circumstances and 0 where no change occurred. We are interested in these variables partly by way of seeing whether there is evidence of other elements of inter-personal utility between parents and their children, in addition to emigration.

\subsubsection{Changes in quality of social relationships}

In the loneliness model, we include two regressors capturing changes in respondents' quality of social relationships. These are derived from a number of questions asked in the self-completion questionnaire aimed to assess the extent to which respondents receive 'social support' or are affected by 'relationship strain' (Ailshire and Crimmins 2011; Schuster et al. 1990; Stafford et al. 2011).

Social support is captured by three items covering empathy, dependability and confiding which are asked of respondents four times to capture relationships with spouse or partner, children, other immediate family and friends. Relationship strain is captured by four items covering criticism, demands, annoyance and being let down, which are also asked of respondents for each relationship type. The items are summed to create a social support scale and a relationship strain scale for all types of relationship combined. ${ }^{3}$ Positive changes in the social support scale indicate that social support has increased. Positive changes in the relationship strain scale indicate that relationship strain has increased.

\footnotetext{
${ }^{3}$ Social support is measured with the following three items: How much do they really understand the way you feel about things? How much can you rely on them if you have a serious problem? How much can you open up to them if you need to talk about your worries? Relationship strain is measured with the following four items: How much do they make too many demands on you? How much do they criticise you? How much do they let you down when you are counting on them? How much do they get on your nerves? Possible responses for each type of relationship are 'A lot' (coded as 3), 'Some' (coded as 2), 'A little' (coded as 1) or 'Not at all' (coded as 0). The social support scale ranges from 0 (no support) to 36 (extreme support); the relationship strain scale ranges from 0 (no strain) to 45 (extreme strain).
} 


\section{Result}

\subsection{Baseline regression results}

Before moving to the fixed-effects models, we investigate associations between child migration and parental mental health in the period preceding the sharp increase in emigration rates. For this purpose, we use wave 1 data only. We include in the sample parents who had a child living abroad at wave $1(N=2302)$ and parents all of whose children were living in Ireland at wave $1\left(N=3652^{4}\right)$. One should note that the 2302 parents with a child living abroad at wave 1 are then excluded from our main fixed-effects model, as our interest in that model is to get as pure a measure as possible of the impact of child emigration on parental mental health. In the interest of completeness, fixed-effects models including also parents with a child living abroad at wave 1 are presented in the Appendix.

Table 1 presents OLS estimates that measure the associations between child migration and (standardised) parental CES-D score. The model also controls for socio-demographic, economic and physical health characteristics and for children's circumstances. Mothers and fathers are firstly looked at together and then separately. The results of Table 1 show that child migration is positively associated with parental depressive symptoms. This association remains statistically significant when the analysis is based on mothers only but is insignificant for fathers.

For the interpretation of the point estimates, it is important to remember that the outcome variable is expressed as standardised $z$-scores. The coefficient of 0.0575 on the child emigration dummy variable indicates that child emigration is associated with a 0.0575 standard deviation increase in depressive symptoms. As the mean (standard deviation) of the CES-D score is 5.9 (7.2), we conclude that the association between parental mental health and child migration is relatively small in magnitude, although statistically significant. ${ }^{5}$

In Table 2, we repeat the analysis of Table 1 but now also investigate the associations of child migration with parental self-reported mental health and loneliness. Child migration is expressed as a dummy variable in panel 1 (yes/no) and as a proportion in panel 2. In general, we find positive associations for mothers and, for loneliness, also positive associations for fathers. To understand the magnitude of these associations, we note that the standard deviations of self-reported mental health and loneliness are 0.98 and 2.12, respectively (1.0 and 2.19 for mothers and 0.95 and 2.02 for fathers).

\footnotetext{
${ }^{4}$ The sample used in the fixed-effects model is smaller than 3652 as it excludes parents who participated at wave 1 but dropped out by wave 2, due to death or other attrition; parents who participated at wave 2 but had missing values in one or more of the variables used in the analysis; and parents aged 76 or more at wave 2 .

${ }^{5}$ The corresponding figures for mothers are 6.8 (7.7); for fathers they are 4.8 (6.3).
} 
Table 1 Results of OLS regression at baseline (wave 1)

\begin{tabular}{|c|c|c|c|c|c|c|}
\hline & \multicolumn{2}{|c|}{ Mothers and fathers } & \multicolumn{2}{|l|}{ Mothers only } & \multicolumn{2}{|l|}{ Fathers only } \\
\hline & Coeff. & $t$ stat. & Coeff. & $t$ stat. & Coeff. & $t$ stat. \\
\hline \multicolumn{7}{|l|}{ Socio-demographic variables } \\
\hline Male & $-0.187^{* * *}$ & $(-6.83)$ & - & - & - & - \\
\hline Age & $-0.0176^{* * *}$ & $(-8.29)$ & $-0.0214^{* * *}$ & $(-7.96)$ & $-0.0125^{* * *}$ & $(-4.06)$ \\
\hline \multicolumn{7}{|l|}{ Reference: primary education } \\
\hline Intermediary education & $-0.0742^{* *}$ & $(-2.43)$ & $-0.0992^{* *}$ & $(-2.23)$ & -0.0308 & $(-0.74)$ \\
\hline Tertiary/higher education & -0.0556 & $(-1.61)$ & $-0.0827^{*}$ & $(-1.65)$ & -0.0129 & $(-0.28)$ \\
\hline Married/cohabiting & $-0.275^{* * *}$ & $(-7.77)$ & $-0.298^{* * *}$ & $(-6.68)$ & $-0.252^{* * *}$ & $(-4.65)$ \\
\hline $2+$ close friends/relatives & $-0.516^{* *}$ & $(-2.41)$ & $-0.683^{* *}$ & $(-2.46)$ & -0.352 & $(-1.11)$ \\
\hline \multicolumn{7}{|l|}{ Health variables } \\
\hline Number of ADL limitations & $0.208^{* * *}$ & $(5.53)$ & $0.245^{* * *}$ & $(4.94)$ & $0.168^{* * *}$ & $(3.02)$ \\
\hline Number of IADL limitations & $0.170^{* * *}$ & $(5.00)$ & $0.139^{* * *}$ & $(3.26)$ & $0.202^{* * *}$ & $(3.78)$ \\
\hline Number of cardiovascular disorders & 0.0246 & $(0.91)$ & 0.0740 & $(1.59)$ & -0.0150 & $(-0.49)$ \\
\hline Number of chronic illnesses & 0.0162 & $(1.42)$ & 0.0125 & $(0.81)$ & 0.0205 & $(1.22)$ \\
\hline Self-rated physical health & $0.213^{* * *}$ & $(14.02)$ & $0.245^{* * *}$ & $(12.19)$ & $0.173^{* * *}$ & $(8.10)$ \\
\hline \multicolumn{7}{|l|}{ Economic variables } \\
\hline \multicolumn{7}{|l|}{ Reference: employed } \\
\hline Retired & $0.138^{* * *}$ & $(3.99)$ & $0.139^{* * *}$ & $(2.59)$ & $0.125^{* *}$ & $(2.52)$ \\
\hline Unemployed & $0.324^{* * *}$ & $(4.07)$ & $0.248^{* *}$ & $(2.06)$ & $0.383^{* * *}$ & $(3.58)$ \\
\hline Other & $0.186^{* * *}$ & $(4.35)$ & $0.187^{* * *}$ & $(3.45)$ & 0.128 & $(1.42)$ \\
\hline \multicolumn{7}{|c|}{ Reference: weekly individual gross income, 1 st tercile } \\
\hline $\begin{array}{l}\text { Weekly individual gross } \\
\text { income, 2nd tercile }\end{array}$ & $-0.0656^{* *}$ & $(-2.09)$ & -0.0519 & $(-1.20)$ & -0.0706 & $(-1.37)$ \\
\hline $\begin{array}{l}\text { Weekly individual gross } \\
\text { income, 3rd tercile }\end{array}$ & -0.0496 & $(-1.53)$ & -0.0684 & $(-1.35)$ & -0.0512 & $(-1.09)$ \\
\hline \multicolumn{7}{|l|}{ Children's circumstances } \\
\hline Number of children & $-0.0179^{* *}$ & $(-2.07)$ & -0.0178 & $(-1.59)$ & -0.0167 & $(-1.41)$ \\
\hline Child emigration & $0.0575^{* *}$ & $(2.13)$ & $0.0665^{*}$ & $(1.81)$ & 0.0462 & $(1.27)$ \\
\hline Child unemployment & $0.126^{* * *}$ & $(3.73)$ & $0.184^{* * *}$ & $(4.03)$ & 0.0387 & $(0.89)$ \\
\hline $\begin{array}{l}\text { Child single/separated/ } \\
\text { divorced/widower }\end{array}$ & 0.00392 & $(0.13)$ & -0.0151 & $(-0.36)$ & 0.0330 & $(0.73)$ \\
\hline$N$ & 5954 & & 3474 & & 2480 & \\
\hline$R^{2}$ & 0.200 & & 0.206 & & 0.161 & \\
\hline
\end{tabular}

The outcome variable is (standardised) CES-D score

Parameter estimates and standard errors are adjusted for the study design using the SVY commands in STATA 12.0

${ }^{*} p<0.10 ;{ }^{* *} p<0.05 ;{ }^{* * *} p<0.01$ 
Table 2 Results of OLS regressions at baseline (wave 1)

\begin{tabular}{|c|c|c|c|c|c|c|}
\hline & \multicolumn{2}{|c|}{ Mothers and fathers } & \multicolumn{2}{|c|}{ Mothers only } & \multicolumn{2}{|c|}{ Fathers only } \\
\hline & Coeff. & $t$ stat. & Coeff. & $t$ stat. & Coeff. & $t$ stat. \\
\hline \multicolumn{7}{|l|}{ Panel 1} \\
\hline Self-rated mental health score & $0.0475^{*}$ & $(1.77)$ & $0.0657^{* *}$ & $(2.03)$ & 0.0219 & $(0.54)$ \\
\hline Loneliness score & $0.122^{* * *}$ & $(3.77)$ & $0.147^{* * *}$ & $(3.40)$ & $0.0873^{*}$ & $(1.88)$ \\
\hline \multicolumn{7}{|l|}{ Panel 2} \\
\hline CES-D score & 0.0729 & $(1.58)$ & 0.0783 & $(1.27)$ & 0.0720 & (1.13) \\
\hline Self-rated mental health score & 0.0616 & $(1.26)$ & $0.134^{* *}$ & $(2.24)$ & -0.0288 & $(-0.42)$ \\
\hline Loneliness score & $0.215^{* * *}$ & $(3.56)$ & $0.230^{* * *}$ & $(2.76)$ & $0.181^{* *}$ & $(2.12)$ \\
\hline
\end{tabular}

Outcome variables are (standardised) CES-D score, self-rated mental health score and loneliness score. Coefficient and $t$ statistics reported for child emigrating dummy (panel 1) and proportion of children emigrating (panel 2)

The explanatory variables listed in Table 1 are included as controls. Parameter estimates and standard errors are adjusted for the study design using the SVY commands in STATA 12.0. The loneliness model is based on a lower number of observations, as the loneliness questions are in the self-completion questionnaire

${ }^{*} p<0.10 ;{ }^{* *} p<0.05 ;{ }^{* * *} p<0.01$

\subsection{Descriptive statistics of parents included in fixed-effects models}

We now turn to the variables used in our fixed-effects models based on a sample including only parents all of whose children were living in Ireland at wave 1 . Table 3 illustrates the summary statistics for the 2523 parents aged 75 or less in the sample, distinguished by the migration status of their children. The table illustrates the changes observed in the scores measuring mental health and the frequencies of events occurring between the two waves. Once again, mothers and fathers are firstly looked at together and then separately.

The first two columns of Table 3 show that while parents of non-emigrating children have experienced, on average, a decrease in depressive symptoms, parents of emigrating children have experienced, on average, an increase in depressive symptoms. The difference between the two groups is statistically significant at the $10 \%$ level. The third and fourth columns show that there exist significant differences in changes in depressive symptoms, self-rated mental health and loneliness feelings for mothers of emigrating children as compared to mothers of non-emigrating children. To illustrate, mothers of emigrating children have experienced, on average, an increase in depressive symptoms of 0.58 points. This compares to a decrease of 0.72 points for mothers of non-emigrating children. The last two columns show that there are no differences in changes in the mental health status for fathers of emigrating children and fathers of non-emigrating children. 


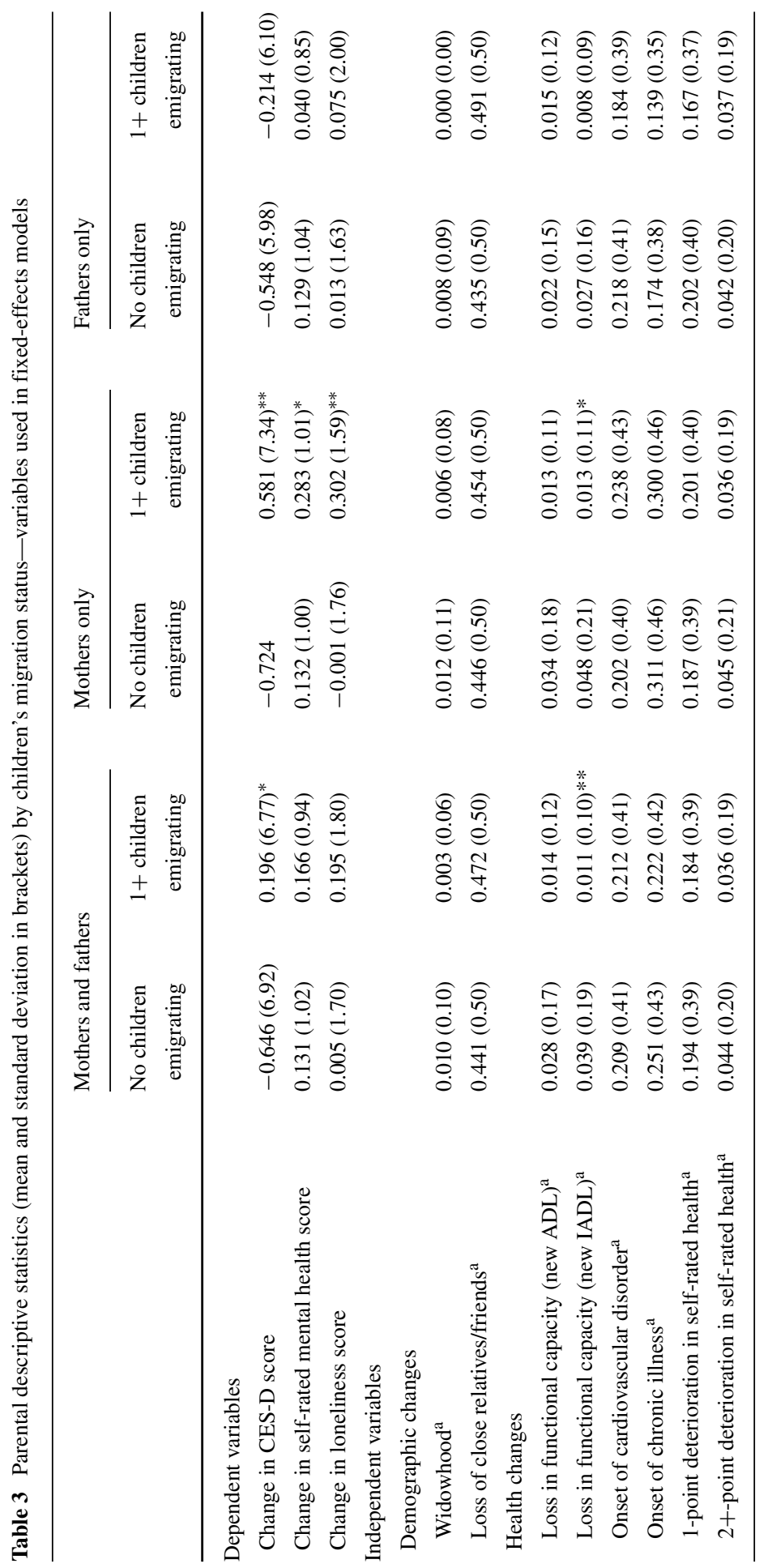




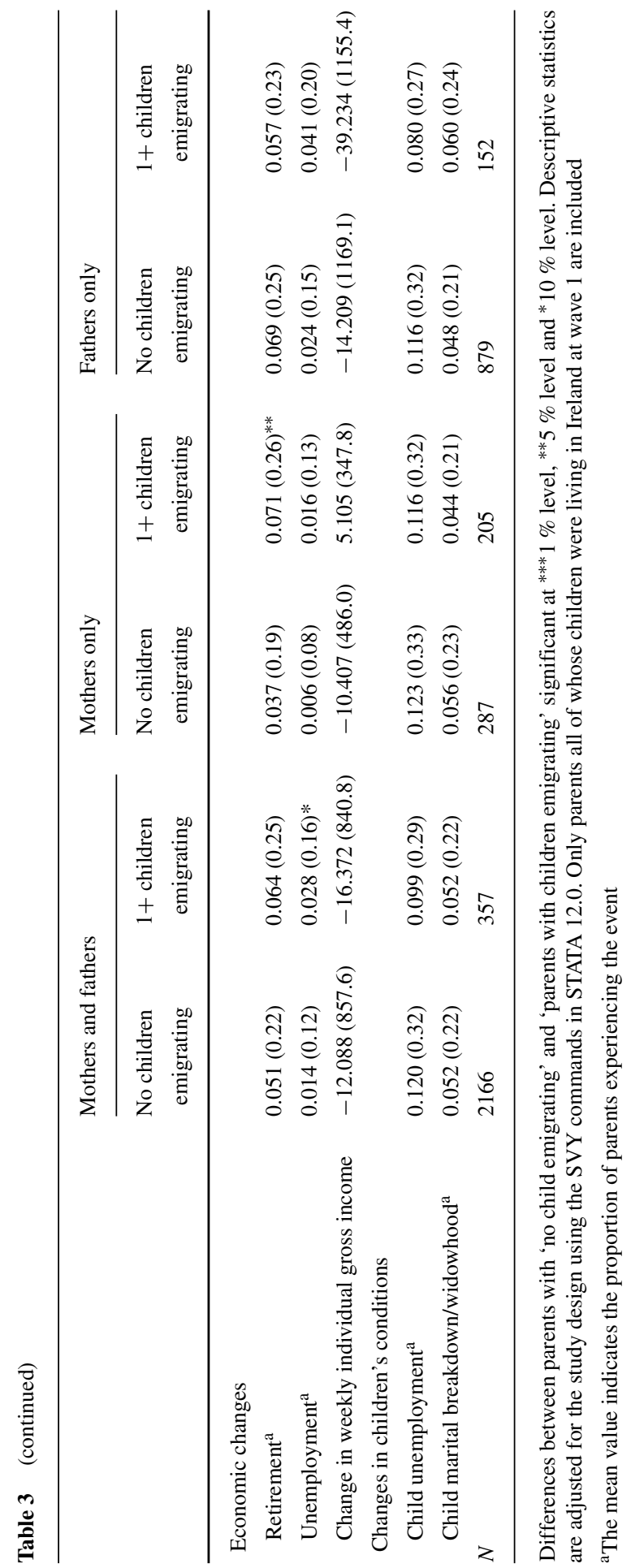


Table 4 investigates whether parents of emigrating children and parents of nonemigrating children differ with respect to (i) (time-invariant) characteristics that are differenced away in Eq. 2 and (ii) baseline mental and physical health status. One can see that mothers and fathers of emigrating children are on average younger, more likely to be highly educated and in better physical health at baseline. Mothers of emigrating children also have lower depression, mental health and loneliness scores at baseline. Analyses not reported here illustrate that important differences also emerge among emigrating and non-emigrating children. The average age of emigrating children is 28.3 years and $40.3 \%$ of children in this group are highly educated. These compare to an average age of 33.4 years and a total of $30.1 \%$ with high education for non-emigrating children.

Before reporting the results of our fixed-effects models, we need to reflect on the problem of attrition that exists in most longitudinal datasets, including TILDA. In analyses not reported here, but available on request, we compared baseline descriptive statistics for parents who participated at wave 1, were still in the sample at wave 2 and dropped out by wave 2, due to death or other attritions. Unsurprisingly, we found that parents who dropped out by wave 2 were more likely to be older, less educated and in poorer physical and mental health at baseline. Although this poses a number of complications to the analysis, it is important to note that participation at wave 2 was high (response rate of $86 \%$ ) and that survey weights were used in our analyses to adjust both for the complex survey design and for using data from the two waves.

\subsection{Fixed-effects regression results}

Tables 5, 6 and 7 report the results of the fixed-effects models which we have put into operation by running OLS regressions with respect to (standardised) changes in depressive symptoms (Table 5), self-rated mental health (Table 6) and loneliness feelings (Table 7), all related to changes in the individuals' circumstances. As with the descriptive statistics, the results are presented first for mothers and fathers together and then for mothers and fathers separately.

Focusing first on our variable of interest, Tables 5, 6 and 7 show that the emigration of a child has a negative effect on the mental health status of the mothers left behind. Mothers of emigrating children are found to experience higher depressive symptoms, a deterioration in self-rated mental health and higher feelings of loneliness. For example, Table 5 shows that, controlling for other events, the change in depression symptoms experienced by mothers of an emigrating child is 0.207 standard deviation greater than the change experienced by mothers of non-emigrating children. Similarly, the results of Table 7 show that the change in loneliness feelings experienced by mothers of an emigrating child is 0.269 standard deviation greater than the change experienced by mothers of non-emigrating children. In contrast, no effects are found for fathers.

Turning to the other events occurring between the two waves, strong negative effects are found for a number of demographic, socioeconomic and physical health events. Not surprisingly, conjugal bereavement is responsible for higher depressive symptoms for both mothers and fathers. Similarly, onset of a cardiovascular disorder, deterioration in self-rated physical health and retirement are associated with higher 


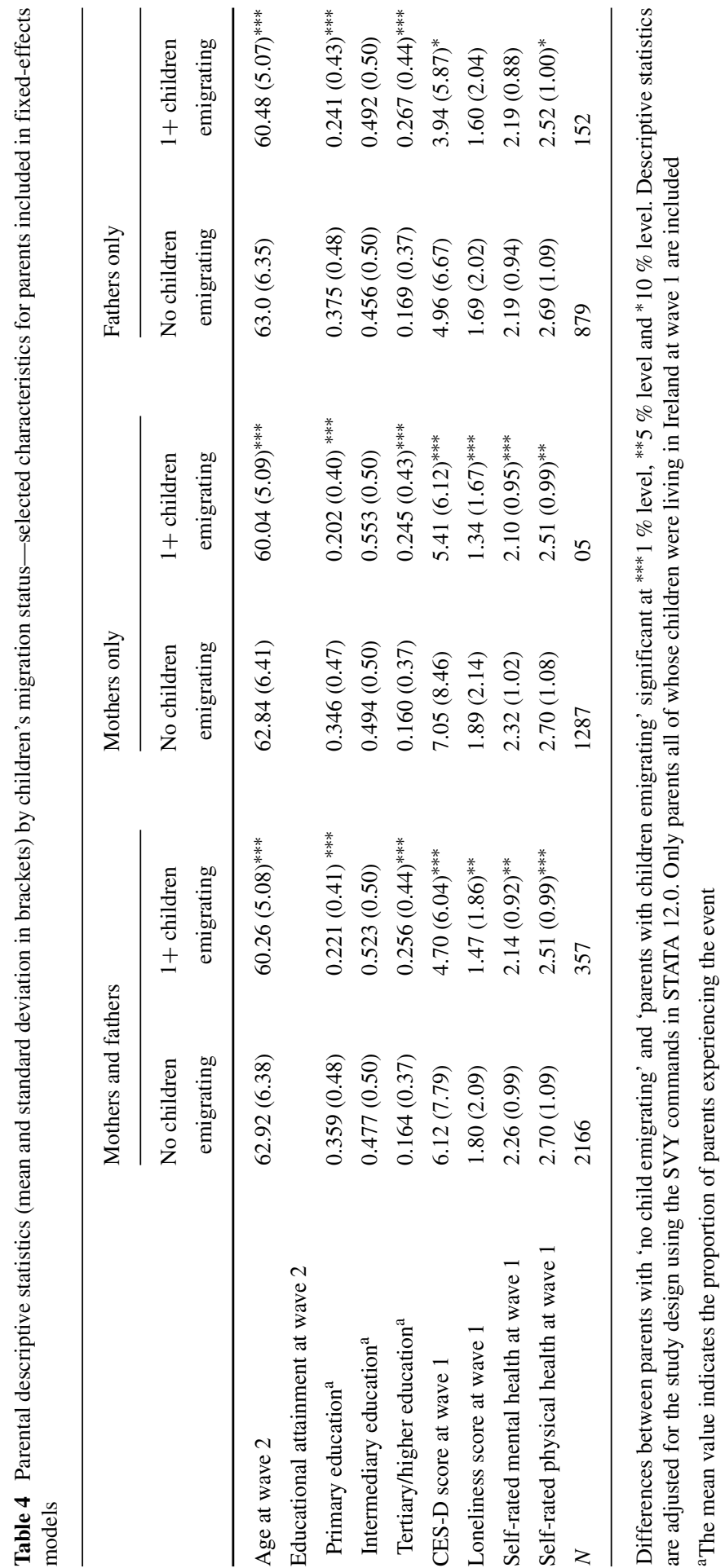


Table 5 Results of OLS regression

\begin{tabular}{|c|c|c|c|c|c|c|}
\hline & \multicolumn{2}{|c|}{ Mothers and fathers } & \multicolumn{2}{|c|}{ Mothers only } & \multicolumn{2}{|c|}{ Fathers only } \\
\hline & Coeff. & $t$ stat. & Coeff. & $t$ stat. & Coeff. & $t$ stat. \\
\hline Widowhood & $0.846^{* * *}$ & $(3.90)$ & $0.847^{* * *}$ & $(3.06)$ & $0.854^{* *}$ & $(2.48)$ \\
\hline Loss of close relatives/friends & $0.0847^{*}$ & $(1.70)$ & $0.170^{* *}$ & $(2.49)$ & -0.0259 & $(-0.41)$ \\
\hline Loss in functional capacity (new ADL) & 0.200 & $(1.07)$ & 0.276 & $(1.08)$ & 0.0393 & $(0.18)$ \\
\hline Loss in functional capacity (new IADL) & 0.119 & $(0.69)$ & 0.147 & $(0.70)$ & 0.111 & $(0.37)$ \\
\hline Onset of cardiovascular disorder & $0.114^{*}$ & $(1.91)$ & 0.116 & $(1.34)$ & $0.111^{*}$ & $(1.65)$ \\
\hline Onset of chronic illness & 0.0710 & $(1.26)$ & 0.0944 & $(1.25)$ & 0.0239 & $(0.28)$ \\
\hline 1-point deterioration in self-rated health & $0.111^{* *}$ & $(2.02)$ & $0.215^{* * *}$ & $(2.78)$ & -0.0177 & $(-0.24)$ \\
\hline $2+$-point deterioration in self-rated health & $0.364^{* * *}$ & $(2.89)$ & 0.231 & $(1.38)$ & $0.559^{* * *}$ & $(2.93)$ \\
\hline Retirement & $0.162^{* *}$ & $(2.55)$ & 0.163 & $(1.59)$ & $0.138^{*}$ & $(1.79)$ \\
\hline Unemployment & 0.105 & $(0.54)$ & -0.401 & $(-1.04)$ & 0.314 & $(1.59)$ \\
\hline Change in income (000s) & -0.00432 & $(-0.27)$ & -0.0121 & $(-0.35)$ & -0.000442 & $2(-0.03)$ \\
\hline Child emigration & $0.139^{* *}$ & $(2.00)$ & $0.207^{* *}$ & $(2.28)$ & 0.0638 & $(0.77)$ \\
\hline Child unemployment & 0.0613 & $(0.86)$ & 0.105 & $(1.10)$ & -0.00315 & $(-0.03)$ \\
\hline Child marital breakdown/widowhood & 0.106 & $(0.83)$ & 0.158 & $(0.93)$ & 0.00521 & $(0.04)$ \\
\hline Constant & \multicolumn{5}{|c|}{$-0.201 * * *(-5.06)-0.286 * * *(-4.90)-0.0930 *$} & $(-1.83)$ \\
\hline$N$ & 2523 & & 1492 & & 1031 & \\
\hline$R^{2}$ & 0.025 & & 0.034 & & 0.031 & \\
\hline
\end{tabular}

The outcome variable is (standardised) change in CES-D score between waves

For events like widowhood or retirement, the change between the two waves is a dichotomous variable equal to 1 if the event happened and 0 otherwise. Parameter estimates and standard errors are adjusted for the study design using the SVY commands in STATA 12.0. Only parents all of whose children were living in Ireland at wave 1 are included

${ }^{*} p<0.10 ;{ }^{* *} p<0.05 ;{ }^{* * *} p<0.01$

depressive symptoms for both mothers and fathers. Onset of a chronic illness, loss of functional capacity and loss of close friends or relatives are associated with higher depressive symptoms for mothers. By way of comparison, the point estimate on the child migration variable for mothers is similar in magnitude to the estimated effects on depressive symptoms of a one-point and two-point deteriorating health ( 0.215 and $0.231)$; it is greater than the estimated effect of the loss of a close friend or relative (0.170).

Table 7 also shows that changes in social support and relationship strain are strong predictors of changes in loneliness feelings for both mothers and fathers. Greater social support is associated with lower loneliness feelings for both mothers and fathers. A greater relationship strain score is associated with greater loneliness feelings for both mothers and fathers.

As explained in Section 3, we also include demographic, socioeconomic and physical health events in our fixed-effects model because (i) they have been found to be strong predictors of (changes in) mental health and (ii) we want to ensure that these 
Table 6 Results of OLS regression

\begin{tabular}{|c|c|c|c|c|c|c|}
\hline & \multicolumn{2}{|c|}{ Mothers and fathers } & \multicolumn{2}{|c|}{ Mothers only } & \multicolumn{2}{|c|}{ Fathers only } \\
\hline & Coeff. & $t$ stat. & Coeff. & $t$ stat. & Coeff. & $t$ stat. \\
\hline Widowhood & 0.117 & $(0.49)$ & 0.225 & $(0.71)$ & -0.138 & $(-0.48)$ \\
\hline Loss of close relatives/friends & 0.0276 & $(0.64)$ & 0.00959 & $(0.18)$ & 0.0476 & $(0.72)$ \\
\hline Loss in functional capacity (new ADL) & 0.0242 & $(0.17)$ & 0.140 & $(0.72)$ & -0.190 & $(-0.97)$ \\
\hline Loss in functional capacity (new IADL) & 0.0923 & $(0.74)$ & 0.0571 & $(0.37)$ & 0.187 & $(0.95)$ \\
\hline Onset of cardiovascular disorder & 0.0331 & $(0.62)$ & 0.00407 & $(0.05)$ & 0.0662 & $(0.87)$ \\
\hline Onset of chronic illness & $0.0908^{*}$ & $(1.93)$ & $0.116^{* *}$ & $(2.01)$ & 0.0391 & $(0.44)$ \\
\hline 1-point deterioration in self-rated health & $0.452^{* * *}$ & $(8.31)$ & $0.411^{* * * *}$ & $(5.64)$ & $0.491^{* * * *}$ & $(6.65)$ \\
\hline $2+$-point deterioration in self-rated health & $0.952^{* * *}$ & $(8.17)$ & $0.859^{* * *}$ & $(6.11)$ & $1.089^{* * *}$ & $(5.55)$ \\
\hline Retirement & $0.145^{*}$ & $(1.81)$ & 0.0734 & $(0.62)$ & $0.203^{*}$ & $(1.91)$ \\
\hline Unemployment & 0.190 & $(1.07)$ & 0.198 & $(0.80)$ & 0.218 & $(0.99)$ \\
\hline Change in income (000s) & -0.0164 & $(-0.98)$ & 0.0152 & $(0.37)$ & -0.0231 & $(-1.18)$ \\
\hline Child emigration & 0.0481 & $(0.86)$ & $0.156^{* *}$ & $(2.03)$ & -0.0634 & $(-0.79)$ \\
\hline Child unemployment & 0.0647 & $(0.90)$ & 0.141 & $(1.64)$ & -0.0329 & $(-0.30)$ \\
\hline Child marital breakdown/widowhood & 0.0183 & $(0.17)$ & 0.0897 & $(0.78)$ & -0.0720 & $(-0.46)$ \\
\hline Constant & $-0.198^{* * *}$ & $(-5.39)$ & $-0.193^{* * *}$ & $(-3.92)$ & $-0.204^{* * *}$ & $(-3.94)$ \\
\hline$N$ & 2523 & & 1492 & & 1031 & \\
\hline$R^{2}$ & 0.069 & & 0.064 & & 0.086 & \\
\hline
\end{tabular}

The outcome variable is (standardised) change in self-rated mental health score between waves

Parameter estimates and standard errors are adjusted for the study design using the SVY commands in STATA 12.0. Only parents all of whose children were living in Ireland at wave 1 are included

${ }^{*} p<0.10 ;{ }^{* *} p<0.05 ;{ }^{* * *} p<0.01$

events are not confined to the time-varying error term. In alternative specifications, we add these changes incrementally and investigate the impact of adding controls on the coefficient of the emigrating child variable. In general, the results of our main fixed-effects model are confirmed, as the coefficient of the emigrating child variable remains statistically significant and positive. ${ }^{6}$

Next, we repeat the analysis of Tables 5, 6 and 7 controlling for the proportion of children emigrating between the two waves. Around $29 \%$ of parents of emigrating children in our sample see $50 \%$ of their children emigrate. This compares to 19 and $6 \%$ of parents seeing 25 and $100 \%$ of their children emigrate, respectively. We expect to find that parents who see a higher proportion of children emigrate experience a greater deterioration in mental health.

\footnotetext{
${ }^{6}$ Results are available on request.
} 
Table 7 Results of OLS regression

\begin{tabular}{|c|c|c|c|c|c|c|}
\hline & \multicolumn{2}{|c|}{ Mothers and fathers } & \multicolumn{2}{|c|}{ Mothers only } & \multicolumn{2}{|l|}{ Fathers only } \\
\hline & Coeff. & $t$ stat. & Coeff. & $t$ stat. & Coeff. & $t$ stat. \\
\hline Widowhood & $0.621^{* *}$ & $(2.16)$ & $0.668^{*}$ & $(1.76)$ & $0.676^{* *}$ & $(2.26)$ \\
\hline Loss of close relatives/friends & 0.0550 & $(1.08)$ & 0.0756 & $(1.12)$ & 0.0396 & $(0.51)$ \\
\hline Social support & $-0.0403^{* * *}$ & $(-5.70)$ & $-0.0474^{* * *}$ & $(-5.00)$ & $-0.0347^{* * *}$ & $(-3.68)$ \\
\hline Relationship strain & $0.0269^{* * *}$ & $(4.42)$ & $0.0294^{* * *}$ & $(3.41)$ & $0.0247^{* * *}$ & $(3.08)$ \\
\hline Loss in functional capacity (new ADL) & -0.105 & $(-0.36)$ & -0.0750 & $(-0.19)$ & -0.149 & $(-0.52)$ \\
\hline Loss in functional capacity (new IADL) & -0.102 & $(-0.55)$ & -0.0477 & $(-0.21)$ & -0.296 & $(-0.91)$ \\
\hline Onset of cardiovascular disorder & $-0.113 *$ & $(-1.72)$ & $-0.156 *$ & $(-1.72)$ & -0.0567 & $(-0.62)$ \\
\hline Onset of chronic illness & 0.0729 & $(1.20)$ & 0.130 & $(1.64)$ & -0.0909 & $(-0.85)$ \\
\hline 1-point deterioration in self-rated health & 0.0586 & $(0.90)$ & $0.162^{*}$ & $(1.85)$ & -0.0622 & $(-0.65)$ \\
\hline 2-point deterioration in self-rated health & 0.0576 & $(0.50)$ & 0.258 & $(1.45)$ & -0.150 & $(-1.14)$ \\
\hline Retirement & -0.0306 & $(-0.39)$ & -0.0412 & $(-0.31)$ & -0.0238 & $(-0.23)$ \\
\hline Unemployment & 0.222 & $(1.27)$ & 0.0985 & $(0.27)$ & 0.306 & $(1.38)$ \\
\hline Change in income (000s) & 0.00484 & $(0.28)$ & -0.0516 & $(-1.41)$ & 0.0166 & $(0.81)$ \\
\hline Child emigration & $0.137^{*}$ & $(1.76)$ & $0.269^{* * *}$ & $(3.03)$ & 0.0131 & $(0.10)$ \\
\hline Child unemployment & 0.0310 & $(0.30)$ & -0.105 & $(-0.79)$ & 0.215 & $(1.45)$ \\
\hline Child marital breakdown/widowhood & 0.0813 & $(0.69)$ & 0.0670 & $(0.51)$ & 0.124 & $(0.61)$ \\
\hline Constant & -0.0596 & $(-1.35)$ & -0.0923 & $(-1.51)$ & -0.0269 & $(-0.43)$ \\
\hline$N$ & 1557 & & 902 & & 655 & \\
\hline$R^{2}$ & 0.078 & & 0.103 & & 0.078 & \\
\hline
\end{tabular}

The outcome variable is (standardised) change in UCLA loneliness score between waves

The loneliness model is based on a lower number of observations, as the loneliness questions are in selfcompletion questionnaire. Parameter estimates and standard errors are adjusted for the study design using the SVY commands in STATA 12.0. Only parents all of whose children were living in Ireland at wave 1 are included

${ }^{*} p<0.10 ;{ }^{* *} p<0.05 ;{ }^{* * *} p<0.01$

Results are presented in Table 8. Holding other factors fixed, the change in depressive symptoms experienced by mothers who see all of their children emigrate is 0.491 standard deviation greater than the change experienced by mothers of non-emigrating children. Similarly, mothers who see all their children emigrate experience a greater deterioration in self-rated mental health as compared to mothers of non-emigrating children.

\subsubsection{Further efforts to address reverse causation}

While the fixed-effects approach used above will remove the biases that would result from endogeneity under many circumstances, we want to explore more fully the following potential concern. People with poor mental health may experience faster increases in depressive symptoms compared to others. If this is true, we could be 
Table 8 Results of OLS regressions

\begin{tabular}{|c|c|c|c|c|c|c|}
\hline & \multicolumn{2}{|c|}{ Mothers and fathers } & \multicolumn{2}{|c|}{ Mothers only } & \multicolumn{2}{|c|}{ Fathers only } \\
\hline & Coeff. & $t$ stat. & Coeff. & $t$ stat. & Coeff. & $t$ stat. \\
\hline$\Delta$ CES-D score & $0.252^{*}$ & $(1.87)$ & $0.491^{* * *}$ & $(2.89)$ & 0.00380 & $(0.02)$ \\
\hline$\Delta$ self-rated mental health score & 0.0478 & $(0.41)$ & $0.310^{*}$ & $(1.83)$ & -0.193 & $(-1.18)$ \\
\hline$\Delta$ loneliness score & 0.0656 & $(0.39)$ & 0.296 & $(1.39)$ & -0.164 & $(-0.63)$ \\
\hline
\end{tabular}

Outcome variables are (standardised) changes in CES-D score, self-rated mental health score and loneliness score. The explanatory variable of interest is the proportion of children emigrating between the two waves

The explanatory variables listed in Table 3 are included as controls. Parameter estimates and standard errors are adjusted for the study design using the SVY commands in STATA 12.0. Only parents all of whose children were living in Ireland at wave 1 are included

${ }^{*} p<0.10 ;{ }^{* *} p<0.05 ;{ }^{* * *} p<0.01$

capturing situations in which children emigrate because of the poor mental health of parents and the observed decline in mental health is not caused by the emigration of the child - it is caused by the underlying poor mental health.

In order to see if this type of process is contaminating the results, we take two approaches, both of which are aimed at looking at parents with poor and good mental health separately. First, we restrict the sample to parents who were in good mental health in wave 1 . Second, we draw on data which allows us to identify parents who had earlier histories of mental health problems and use this data to see if our observed effects are still present for parents with no prior histories.

Looking at our first approach, we restrict the sample to parents who did not have clinically significant depressive symptoms at wave 1 (CES-D score $<16$ ). The results of Table 9, panel 1, show that, for mothers, the coefficients of our variables of interest (i.e. child emigration and proportion of children emigrating) are still positive and statistically significant at $10 \%$. We also restrict the sample to parents who reported to be in excellent, very good or good mental health at wave 1. Once again, the coefficients of our variables of interest are still positive and statistically significant at $5 \%$ (10\%) for mothers, as shown in Table 9, panel 2.

Turning to our second approach, TILDA respondents are asked whether they have ever been diagnosed with depression or manic depression. Around $6 \%$ of the parents in our sample (5.2\% of fathers and $6.6 \%$ of mothers) report to have been diagnosed at some point in their life with depression.

We use this data by re-running the model of Eq. 2 and interacting the "child emigrating' binary variable with the binary variable 'past diagnosis of depression'. Results are presented in Table 10, panel 1. Focusing first on mothers with no history of depression, the results of Table 10 show that for these mothers, having an

\footnotetext{
${ }^{7}$ As Wooldridge (2006, p. 488) points out, although time-constant variables cannot be included themselves in a fixed-effects model, they can be interacted with variables that change over time.
} 
Table 9 Results of OLS regression

\begin{tabular}{|c|c|c|c|c|c|c|}
\hline & \multicolumn{2}{|c|}{ Mothers and fathers } & \multicolumn{2}{|c|}{ Mothers only } & \multicolumn{2}{|c|}{ Fathers only } \\
\hline & Coeff. & $t$ stat. & Coeff. & $t$ stat. & Coeff. & $t$ stat. \\
\hline \multicolumn{7}{|c|}{ Panel 1: parents with a CES-D score $<16$ at wave 1} \\
\hline Child emigration dummy & 0.0727 & $(1.14)$ & $0.149^{*}$ & $(1.80)$ & -0.00543 & $(-0.07)$ \\
\hline Proportion of children emigrating & 0.126 & $(1.10)$ & $0.285^{*}$ & $(1.77)$ & -0.0336 & $(-0.22)$ \\
\hline$N$ & 2280 & & 1313 & & 967 & \\
\hline \multicolumn{7}{|c|}{ Panel 2: parents who self-rated to be in good, very good or excellent mental health at wave 1} \\
\hline Child emigration dummy & 0.0169 & $(0.29)$ & $0.150^{* *}$ & $(2.03)$ & -0.118 & $(-1.45)$ \\
\hline Proportion of children emigrating & -0.00170 & $(-0.01)$ & $0.295^{*}$ & $(1.76)$ & -0.267 & $(-1.62)$ \\
\hline$N$ & 2288 & & 1334 & & 954 & \\
\hline
\end{tabular}

Outcome variables are (standardised) change in CES-D score between waves (panel 1) and (standardised) change in self-rated mental health between waves (panel 2)

The explanatory variables listed in Table 3 are included as controls. Parameter estimates and standard errors are adjusted for the study design using the SVY commands in STATA 12.0. Only parents all of whose children were living in Ireland at wave 1 are included

${ }^{*} p<0.10 ;{ }^{* *} p<0.05 ;{ }^{* * *} p<0.01$

emigrating child is associated with greater depressive symptoms, but the coefficient is not statistically significant $(t=1.58)$. Turning then to mothers with history of depression, the results of Table 10, panel 1, show that for these mothers having an emigrating child is associated with greater depressive symptoms: the coefficient of the interaction term is large in magnitude and significant at $1 \%$ level. In contrast, mothers with history of depression who did not see a child emigrate experienced lower depressive symptoms.

We then re-employ the basic model again but interact the variable 'proportion of children emigrating' with the binary variable 'past diagnosis of depression'. Results are presented in Table 10, panel 2. Results show that mothers with earlier episodes of depression who see all their children emigrate experience a change in depressive symptoms which is 2.089 standard deviations greater than that experienced by mothers with history of depression who do not see any of their children emigrate. Among mothers with no history of depression, the change in depressive symptoms for those who see all their children emigrate is 0.381 standard deviation greater than that mothers of non-emigrating children. This estimate is statistically significant at $5 \%$ level and so suggests that the effect is not just present for parents with past diagnoses of depression.

\subsubsection{Final thoughts on reverse causation}

If results were purely driven by reverse causation, we would expect the probability of having an emigrating child to be higher for parents who had previously been diagnosed with depression. To test this hypothesis, we employ a probit model in which the dependent variable 'child emigrating between the two survey waves' is regressed 


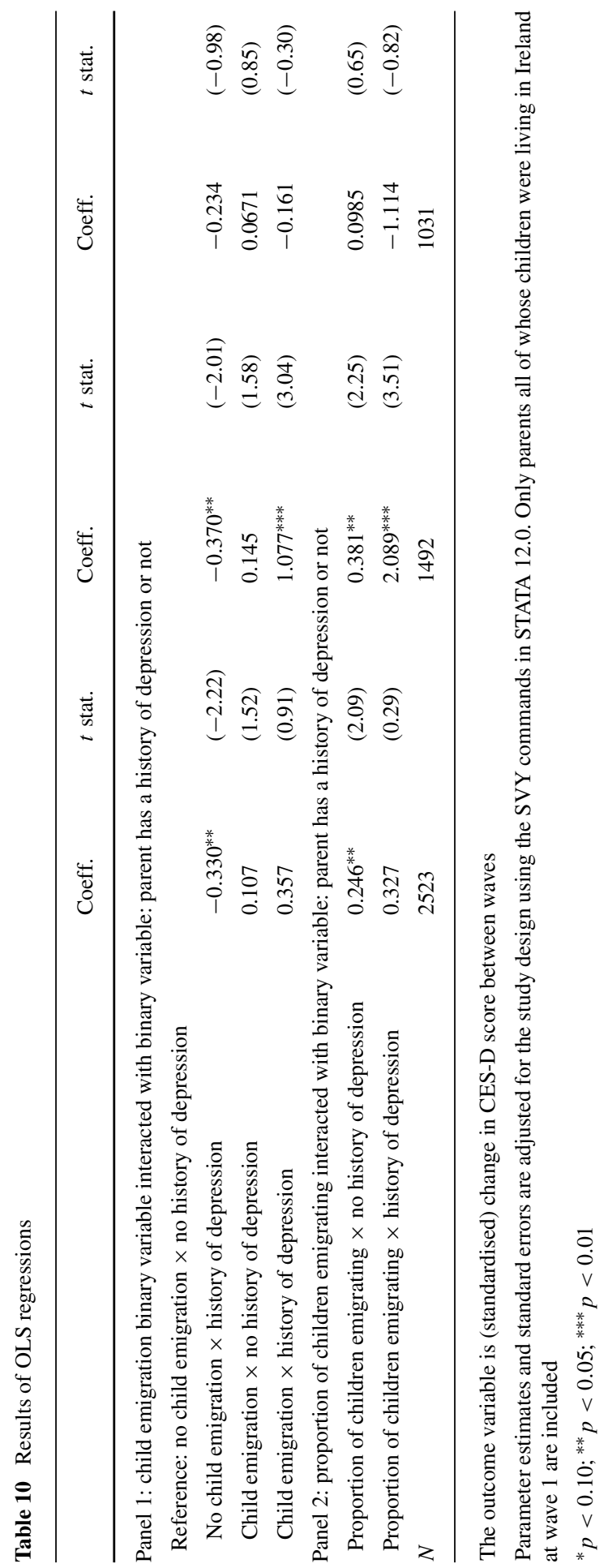


on a number of parental baseline characteristics and past diagnosis of depression. The results of Table 11 show that the probability of seeing a child emigrate between the two survey waves is not higher for parents with a history of depression. If anything,

Table 11 Results of probit model

\begin{tabular}{|c|c|c|c|c|c|c|}
\hline & \multicolumn{2}{|c|}{ Mothers and fathers } & \multicolumn{2}{|l|}{ Mothers only } & \multicolumn{2}{|l|}{ Fathers only } \\
\hline & Coeff. & $t$ stat. & Coeff. & $t$ stat. & Coeff. & $t$ stat. \\
\hline Male & 0.0764 & $(1.18)$ & - & - & - & - \\
\hline Age & $-0.0409^{* * *}$ & $(-5.22)$ & $-0.0394^{* * *}$ & $(-4.21)$ & $-0.0426^{* * *}$ & $(-3.64)$ \\
\hline \multicolumn{7}{|l|}{ Ref: primary education } \\
\hline Intermediary education & $0.163^{*}$ & $(1.72)$ & 0.174 & $(1.35)$ & 0.159 & $(1.19)$ \\
\hline Tertiary/higher education & $0.350^{* * *}$ & $(3.08)$ & $0.299^{* *}$ & $(1.97)$ & $0.426^{* * *}$ & $(2.86)$ \\
\hline \multicolumn{7}{|l|}{ Ref: employed } \\
\hline Retired & -0.182 & $(-1.54)$ & -0.216 & $(-1.30)$ & -0.141 & $(-0.88)$ \\
\hline Other & -0.129 & $(-1.17)$ & -0.104 & $(-0.75)$ & -0.0222 & $(-0.11)$ \\
\hline \multicolumn{7}{|l|}{ Ref: lives in Dublin } \\
\hline Another town/city & -0.108 & $(-0.88)$ & -0.161 & $(-1.19)$ & -0.0116 & $(-0.08)$ \\
\hline Rural area & -0.103 & $(-0.97)$ & -0.176 & $(-1.48)$ & 0.0104 & $(0.08)$ \\
\hline \multicolumn{7}{|l|}{ Ref: income 1st quintile } \\
\hline Income 2nd quintile & -0.0183 & $(-0.16)$ & 0.0217 & $(0.16)$ & -0.134 & $(-0.53)$ \\
\hline Income 3 rd quintile & -0.0680 & $(-0.53)$ & -0.0114 & $(-0.07)$ & -0.223 & $(-1.01)$ \\
\hline Income 4 th quintile & 0.0981 & $(0.79)$ & 0.226 & $(1.45)$ & -0.0730 & $(-0.38)$ \\
\hline Income 5 th quintile & -0.0487 & $(-0.38)$ & 0.0920 & $(0.50)$ & -0.199 & $(-1.08)$ \\
\hline Married/cohabiting & 0.0918 & $(0.88)$ & 0.0325 & $(0.27)$ & 0.253 & $(1.48)$ \\
\hline Number of children & $0.153^{* * *}$ & $(5.81)$ & $0.127^{* * *}$ & $(4.49)$ & $0.191^{* * *}$ & $(5.24)$ \\
\hline Return migrant & $0.256^{* *}$ & $(2.58)$ & 0.174 & $(1.38)$ & $0.322^{* *}$ & $(2.37)$ \\
\hline Past diagnosis of depression & 0.115 & $(0.71)$ & -0.112 & $(-0.47)$ & 0.327 & $(1.39)$ \\
\hline CES-D score & $-0.0129^{*}$ & $(-1.81)$ & $-0.0140^{*}$ & $(-1.85)$ & -0.0120 & $(-1.10)$ \\
\hline \multicolumn{7}{|c|}{ Ref: excellent/very good self-rated health } \\
\hline Good self-rated health & 0.0160 & $(0.19)$ & 0.0171 & $(0.16)$ & 0.0278 & $(0.21)$ \\
\hline Fair/poor self-rated health & -0.0553 & $(-0.42)$ & -0.0792 & $(-0.48)$ & -0.0691 & $(-0.35)$ \\
\hline Past diagnosis of cancer & 0.0473 & $(0.30)$ & -0.0330 & $(-0.17)$ & 0.195 & $(0.71)$ \\
\hline Past diagnosis of heart attack & $-0.682^{* *}$ & $(-2.13)$ & -0.420 & $(-0.90)$ & $-0.909^{* *}$ & $(-2.17)$ \\
\hline Constant & 0.757 & $(1.57)$ & 0.835 & $(1.44)$ & 0.643 & $(0.91)$ \\
\hline$N$ & 2352 & & 1385 & & 967 & \\
\hline
\end{tabular}

Outcome variables are 1 if parent experiences child emigration between the two survey waves and 0 otherwise. Explanatory variables capture parental characteristics at baseline (wave 1)

Parameter estimates and standard errors are adjusted for the study design using the SVY commands in STATA 12.0. Only parents all of whose children were living in Ireland at wave 1 are included

${ }^{*} p<0.10 ;{ }^{* *} p<0.05 ;{ }^{* * *} p<0.01$ 
parents with a higher CES-D score at wave 1 are less likely to see a child emigrate between the two survey waves.

\subsubsection{The characteristics of the parents and of the children}

We now investigate whether the negative effect of child emigration on parental mental health is stronger for parents with certain characteristics. One hypothesis is that child emigration may have a greater negative effect on older parents, who might require more physical care from their children. Parents who were already widowed, separated or divorced at wave 1 may also be at higher risk, as they may lack close substitutes for children if these leave. Around one fifth of parents in our sample are return migrants: they lived abroad for six months or more before returning to Ireland. If parents who are return migrants themselves believe that emigration maximises their children's opportunities, then we may find weaker effects for this group of parents.

To investigate these possibilities, we interact the child emigration binary variable with a number of binary variables capturing parental characteristics. These are as follows: parental age group (aged $\leq 65$ and $65+$ ), parental marital status at wave 1 (married/cohabiting and widowed/separated/divorced) and parental return migration status (return migrant and stayer). Around $15.5 \%$ of parents of emigrating children are aged 65 and above, $86 \%$ were married or cohabiting at wave 1 and $22.2 \%$ are return migrants. Of these, $15.1 \%$ lived abroad for less than ten years before returning to Ireland and the remaining $7.1 \%$ lived abroad for ten years or more. We add the interactions with parental characteristics one at a time. Results are presented in Table 12.

The results of Table 12, panel 1, show the strongest results are found for loneliness. Interestingly, older fathers of an emigrating child experience greater loneliness feelings. The effect of child emigration is estimated to be around 0.532 standard deviation higher for older fathers than for younger fathers. Turning then to the results of Table 12, panel 2, the effect of a child emigration on changes in depressive symptoms, self-rated mental health and loneliness feelings does not seem to differ among parents who were married or widowed/separated/divorced at wave 1 .

Focusing finally on the results of Table 12, panel 3, we find that greater loneliness feelings are experienced by mothers who never left Ireland as compared to mothers who lived abroad for some time. As we find this result interesting, we investigate whether this applies to mothers who spent shorter or longer periods of their life abroad. The results of Table 12, panel 4, and Table 12, panel 5, show that lesser loneliness feelings are experienced by mothers who lived abroad for less than ten years. As these mothers returned to Ireland after spending only few years abroad, they might expect their children to do the same.

Finally, we investigate whether the characteristics of the emigrating child are important in determining the negative effect of child emigration on parental mental health. In particular, we investigate whether it matters if the emigrating child is male or female, is younger (aged 16 to 24) or older (aged 25+), was living with parents or somewhere else in Ireland at wave 1 and had children or was childless at wave 1 data collection. For simplicity purposes, we focus only on parents with one emigrating child and exclude parents with two or more emigrating children. Focusing first on 


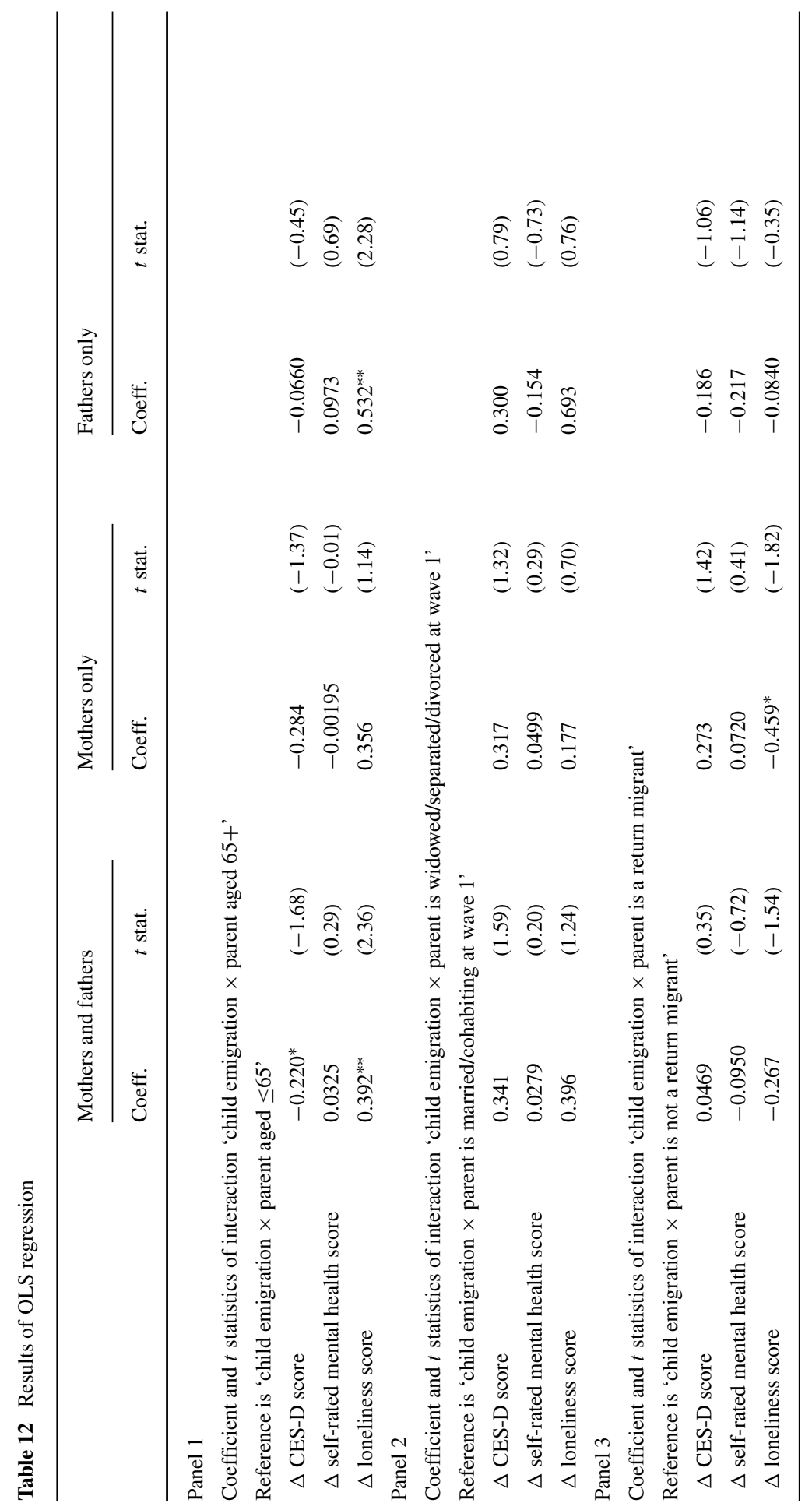




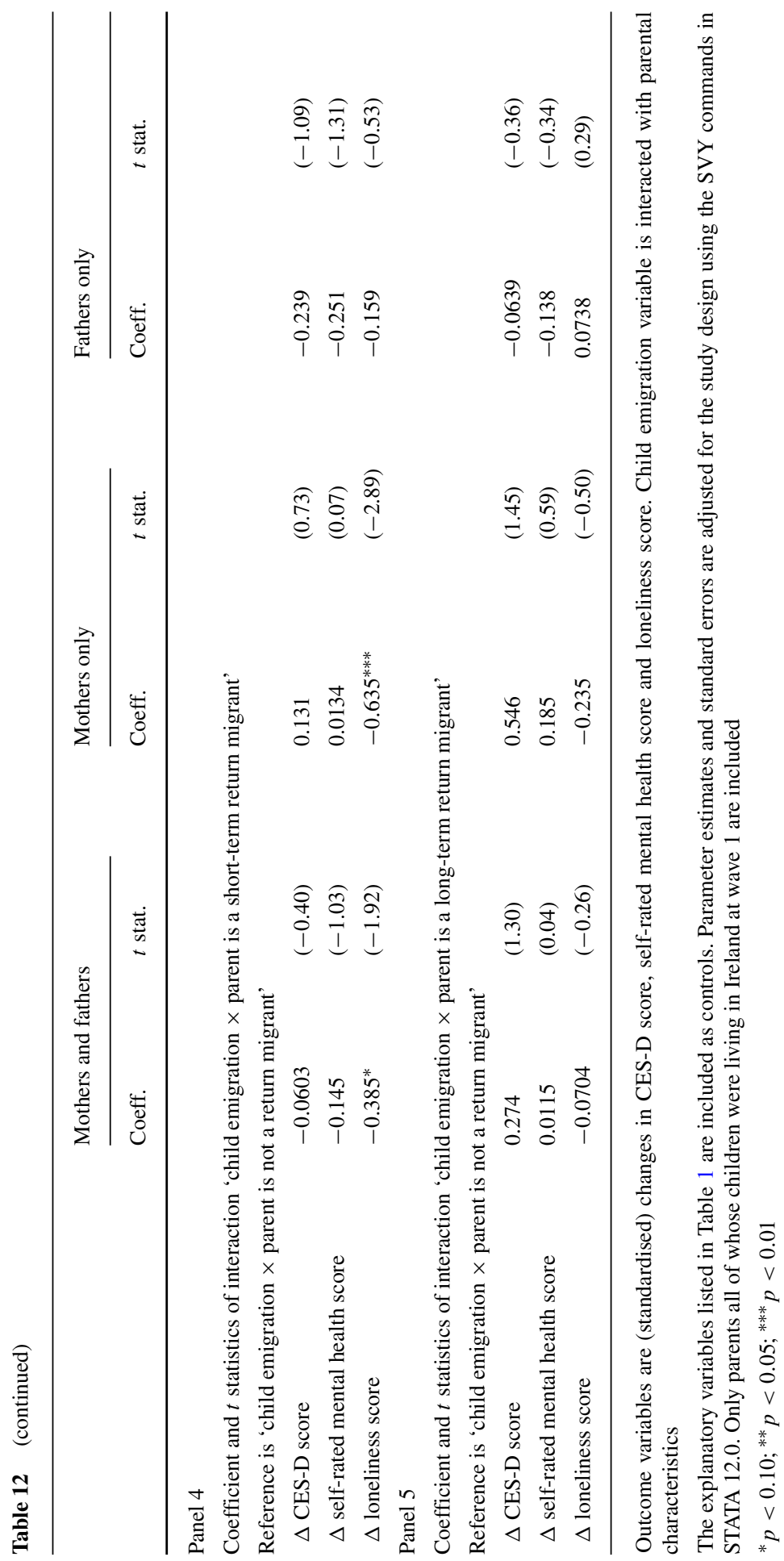


the descriptive statistics, a total of $60.1 \%$ of emigrating children are males, $38.2 \%$ are aged less than $25,41.7 \%$ were living with their parents at wave 1 and $12.5 \%$ had children at wave 1 .

Results for standardised changes in depressive symptoms are presented in Table 13. In terms of magnitude and statistical significance, the effects are stronger for mothers whose emigrating child was female, younger, not cohabiting with parents at wave 1 and a parent herself. In terms of statistically significant differences between the effects caused by the emigration of children with different characteristics, the only significant difference emerges for mothers whose emigrating child had children herself as compared to mothers whose emigrating child was childless. This result is not surprising as in this case the mothers in our sample not only saw a child emigrate but also saw a grandchild emigrate.

Table 13 Results of OLS regressions

\begin{tabular}{|c|c|c|c|c|c|c|}
\hline \multirow[t]{2}{*}{ Outcome variable: $z \Delta$ CES-D score } & \multicolumn{2}{|c|}{ Mothers and fathers } & \multicolumn{2}{|c|}{ Mothers only } & \multicolumn{2}{|c|}{ Fathers only } \\
\hline & Coeff. & $t$ stat. & Coeff. & $t$ stat. & Coeff. & $t$ stat. \\
\hline
\end{tabular}

Emigrating child gender

\begin{tabular}{|c|c|c|c|c|c|c|}
\hline (1) Male & 0.129 & $(1.28)$ & 0.200 & $(1.53)$ & 0.0454 & $(0.40)$ \\
\hline (2) Female & $0.219^{* *}$ & $(2.07)$ & $0.318^{* *}$ & $(2.33)$ & 0.0930 & $(0.66)$ \\
\hline$P$ value of Wald test: $\beta_{(1)}=\beta_{(2)}^{\mathrm{a}}$ & $>0.10$ & & $>0.10$ & & $>0.10$ & \\
\hline \multicolumn{7}{|l|}{ Emigrating child age group } \\
\hline (1) Aged 16-24 & $0.218^{*}$ & $(1.80)$ & $0.403^{* *}$ & $(2.40)$ & 0.00466 & $(0.04)$ \\
\hline (2) Aged 25+ & 0.131 & $(1.39)$ & 0.158 & $(1.39)$ & 0.101 & $(0.84)$ \\
\hline$P$ value of Wald test: $\beta_{(1)}=\beta_{(2)}$ & $>0.10$ & & $>0.10$ & & $>0.10$ & \\
\hline \multicolumn{7}{|c|}{ Emigrating child place of residence at wave 1} \\
\hline (1) Living with parents & 0.134 & $(1.21)$ & 0.162 & $(1.05)$ & 0.0990 & $(0.88)$ \\
\hline (2) Not living with parents & 0.139 & $(1.62)$ & $0.238^{* *}$ & $(2.17)$ & 0.0264 & $(0.23)$ \\
\hline$P$ value of Wald test: $\beta_{(1)}=\beta_{(2)}$ & $>0.10$ & & $>0.10$ & & $>0.10$ & \\
\hline \multicolumn{7}{|l|}{ Emigrating child childbearing status } \\
\hline (1) Has children & $0.484^{*}$ & $(1.76)$ & $0.661^{* *}$ & $(2.37)$ & 0.227 & $(0.61)$ \\
\hline (2) Has no children & 0.118 & $(1.61)$ & $0.174 *$ & $(1.72)$ & 0.0454 & $(0.49)$ \\
\hline$P$ value of Wald test: $\beta_{(1)}=\beta_{(2)}$ & $>0.10$ & & $<0.10$ & & $>0.10$ & \\
\hline
\end{tabular}

Outcome variables are (standardised) changes in CES-D score, self-rated mental health score and loneliness score. Explanatory variables of interest are emigrating child characteristics

For simplicity purposes, only parents with one emigrating child or no emigrating children are included. Parents with two or more emigrating children are excluded. Parameter estimates and standard errors are adjusted for the study design using the SVY commands in STATA 12.0

${ }^{*} p<0.10 ;{ }^{* *} p<0.05 ;{ }^{* * *} p<0.01$

${ }^{a}$ Wald test tests the restriction that the coefficients on the two binary variables (e.g. child emigrating is male and child emigrating is female) are equal 


\section{Conclusions}

In very broad terms, our goal in this paper has been to add to the growing literature on the impacts of emigration on the sending country. More specifically, we have tried to extend the research which has looked within families and sought to identify effects on family members left behind.

In our main model, we restricted the sample to a homogeneous group of parents, which is parents all of whose children were living in Ireland at wave 1. We exploited the fact that much of the emigration from Ireland in the period 2009 to 2013 was the result of an 'exogenous shock' and compared the changes in mental health experienced by parents who saw a child emigrating between the two waves to those of parents all of whose children were still living in Ireland at wave 2.

We found that mothers of migrant children experienced short-term declines in mental health, although in general no evidence of this was found for fathers. The one exception to this was with respect to older fathers and their feelings of loneliness. Our use of fixed-effects modelling and of a wide array of time-varying determinants of mental health should have allowed us to overcome the potential problems associated with time-invariant and time-varying endogeneity, so we are confident when attributing causation. These effects were found while controlling for a number of other life events which would typically impact upon mental health, such as bereavement and the onset of illness. We could not control for remittances, but these are unlikely to be a factor in Ireland given the generosity of the social security system. Focusing on wave 1 data only, we also found that child migration is positively associated with poor parental mental health. The results of the fixed-effects model presented in the Appendix and based on a sample including also parents who already had a child living abroad at wave 1 showed, however, insignificant results.

The result of our main fixed-effects model that only mothers experienced declines in mental health, although somewhat surprising, is in line with previous research that has shown that gender differences exist in relation to the role and importance of personal interactions with spouse, friends and relatives. For example, Schuster et al. (1990) found that frequencies of supportive (negative) interactions with relatives had significant positive (negative) effects on the mood of American women, whereas neither of these effects was significant among men (p. 432). Similarly, Fiori and Denckla (2012) found that the receipt of emotional support was associated with mental health in middle-aged American women. No association was found for men.

Liebler and Sandefur (2002) found that women are more likely to give and receive emotional support and to base personal relationships on emotional closeness. Leavy (1983) and Swain (1992) found that men tend to focus relationships more on shared activities. Also, Dykstra and de Jong Gierveld (2004) found that marriage bonds tend to be more central to the well-being of men than women and argued that whereas men are more likely to find an intimate attachment in marriage, women also find protection from emotional loneliness in other close ties.

Although we cannot directly compare our results with Antman's (2010, 2011 and 2013), we note that, in line with Antman's findings, our results indicate a significant positive association between child migration and poor parental mental health and a stronger effect when endogeneity is accounted for. Unfortunately, as Antman did not 
distinguish between mothers and fathers, we do not know whether the result that the effect is stronger for mothers also holds in the Mexican context.

It is important to note that our estimates likely represent a lower bound. First, as argued above, children of parents who are more prone to mental health problems may be less likely to migrate. Hence, if only children of mentally healthy parents migrate, the estimated effect might be lower than the average effect in the population. Second, we (implicitly) condition on parental survival, both as in being alive and as in remaining in the dataset. Hence, this may exclude those parents who suffer most from their children's absence.

Our core findings are important from three perspectives. First, the most direct implication is that emigration causes pain. While the economics literature has long factored the psychic costs of the individual migrant into analyses, the results here show that there are psychic costs to family members too. Second, emigration through its effect on mental health could impose economics costs on both the public finances and on the economy. As noted by Layard (2013), mentally ill individuals have lower employment rates and those who work are significantly more likely to take time off sick. Treating mental illness (and providing the related social care) costs roughly $1.5 \%$ of GDP in Britain (Layard 2013, p. 6). The total annual cost of mental ill health in the Republic of Ireland was estimated to be around $€ 11$ billion (Expert Group on Mental Health Policy 2006). Third, while Mincer's (1978) model of tied migrants and tied stayers was typically applied to spouses, our results suggest that tied stayers might result from a process whereby children anticipate the likely mental health impact on their parents if they were to emigrate. All of these considerations point to the importance of continued work in this area.

Acknowledgments We would like to thank the Editor and three anonymous referees for their insightful comments. Irene Mosca is supported by a Health Research Board of Ireland grant (ICE/2011/7) under the Interdisciplinary Capacity Enhancement programme. TILDA is funded by Atlantic Philanthropies, the Irish Government Department of Health and Children and Irish Life and Permanent plc.

\section{Compliance with Ethical Standards}

Conflict of interests The authors declare that they have no competing interests.

\section{Appendix}

In the fixed-effects models presented in the paper, we restricted our sample to parents all of whose children were living in Ireland at wave 1 . We did this based on the argument that the analysis of this group would give the cleanest possible estimate of the impact of children's emigration on the mental health of older parents.

In Table 14, we present results of the fixed-effects model in which the (standardised) change in CES-D is the dependent variable, but we expand the sample and the categories of parents affected by migration. The sample now includes all parents participating at both wave 1 and wave 2 . This implies that, in addition to the earlier group, parents who had a child abroad at wave 1 are also included. We include two 
Table 14 Results of OLS regression

\begin{tabular}{|c|c|c|c|c|c|c|}
\hline & \multicolumn{2}{|c|}{ Mothers and fathers } & \multicolumn{2}{|c|}{ Mothers only } & \multicolumn{2}{|c|}{ Fathers only } \\
\hline & Coeff. & $t$ stat. & Coeff. & $t$ stat. & Coeff. & $t$ stat. \\
\hline Widowhood & $0.692^{* * *}$ & $(3.27)$ & $0.758^{* * *}$ & $(3.66)$ & 0.537 & $(1.05)$ \\
\hline Loss of close relatives/friends & $0.0724^{*}$ & $(1.87)$ & $0.0962^{*}$ & $(1.86)$ & 0.0434 & $(0.84)$ \\
\hline Loss in functional capacity (new ADL) & $0.264^{*}$ & $(1.67)$ & 0.306 & $(1.49)$ & 0.190 & $(0.71)$ \\
\hline Loss in functional capacity (new IADL) & 0.144 & $(1.07)$ & 0.0878 & $(0.52)$ & 0.255 & $(1.02)$ \\
\hline Onset of cardiovascular disorder & $0.128^{* * *}$ & $(2.88)$ & $0.159^{* *}$ & $(2.43)$ & 0.0872 & $(1.53)$ \\
\hline Onset of chronic illness & 0.0605 & $(1.35)$ & 0.0633 & $(1.10)$ & 0.0792 & $(1.12)$ \\
\hline 1-point deterioration in self-rated health & $0.131^{* * *}$ & $(2.84)$ & $0.199^{* * *}$ & $(3.29)$ & 0.0402 & $(0.62)$ \\
\hline $2+$-point deterioration in self-rated health & $0.396^{* * *}$ & $(3.96)$ & $0.286^{* *}$ & $(2.08)$ & $0.533^{* * *}$ & $(3.60)$ \\
\hline Retirement & $0.141^{* *}$ & $(2.21)$ & $0.187^{*}$ & $(1.78)$ & 0.0962 & $(1.21)$ \\
\hline Unemployment & 0.216 & $(1.47)$ & 0.0740 & $(0.22)$ & 0.257 & $(1.51)$ \\
\hline Change in income (000s) & -0.00103 & $(-0.08)$ & -0.00742 & $(-0.28)$ & 0.00180 & $(0.11)$ \\
\hline Child emigration & 0.0196 & $(0.33)$ & 0.0570 & $(0.74)$ & -0.0334 & $(-0.47)$ \\
\hline Child return & 0.0437 & $(0.49)$ & -0.00291 & $(-0.02)$ & 0.0806 & $(0.66)$ \\
\hline Child unemployment & 0.0510 & $(0.89)$ & 0.0789 & $(1.10)$ & 0.00561 & $(0.07)$ \\
\hline Child marital breakdown/widowhood & 0.0236 & $(0.27)$ & 0.0419 & $(0.36)$ & -0.0158 & $(-0.15)$ \\
\hline Constant & $-0.179^{* * *}$ & $(-5.75)$ & $-0.236^{* * *}$ & $(-5.25)$ & $-0.108^{* *}$ & $(-2.58)$ \\
\hline$N$ & 3976 & & 2360 & & 1616 & \\
\hline$R^{2}$ & 0.024 & & 0.026 & & 0.029 & \\
\hline
\end{tabular}

The outcome variable is (standardised) change in CES-D score between waves

For events like widowhood or retirement, the change between the two waves is a dichotomous variable equal to 1 if the event happened and 0 otherwise. Parameter estimates and standard errors are adjusted for the study design using the SVY commands in STATA 12.0. Parents with children living in Ireland or abroad at wave 1 are included

${ }^{*} p<0.10 ;{ }^{* *} p<0.05 ;{ }^{* * *} p<0.01$

indicators for whether a parent experienced (i) child emigration and (ii) child return to Ireland between the two survey waves. Parents who did not see a child emigrate or return between the two waves are included in the reference category.

The results of Table 14 show that we no longer find statistically significant results when we expand the analysis. Parents seeing a second or third child emigrate must not suffer the same impact as when the first child goes. Perhaps there is even some mental relief if one child emigrates and joins the earlier-emigrating child. The parent may also be experiencing a weakening in the concern for the first child if that child is overcoming initial difficulties often experienced by immigrants. For the parents who see a child return, the non-significant result could potentially arise from opposing outcomes-happiness on the part of some parents to have a child back home versus sadness if return arose due to a failure in the host country. 


\section{References}

Ailshire JA, Crimmins EM (2011) Psychosocial factors associated with longevity in the United States: age differences between the old and oldest-old in the health and retirement study. Journal of Aging Research. doi:10.4061/2011/530534

Antman FM (2010) Adult child migration and the health of elderly parents left behind in Mexico. Ame Econ Rev 100:205-208

Antman FM (2011) How does adult child migration affect the health of elderly parents left behind? Evidence from Mexico. University of Colorado Boulder Population Programme Working Paper POP2011-09

Antman FM (2013) The impact of migration on family left behind. In: Constant AF, Zimmermann KF (eds) International handbook on the economics of migration. Edward Elgar, Cheltenham, UK and Northampton, USA, pp 293-308

Barrett A, O'Sullivan V (2014) The wealth, health and well-being of Ireland's older people before and during the economic crisis. App Econ Lett 21(10):675-678

Beekman ATF, Deeg DJH, van Tilburg T, et al. (1995) Major and minor depression in later life: a study of prevalence and risk factors. J Affect Disord 36:65-75

Buber I, Engelhardt H (2008) Children's impact on the mental health of their older mothers and fathers: findings from the Survey of Health, Ageing and Retirement in Europe. Eur J Ageing 5:31-45

Choi NG, Bohman TM (2007) Predicting the changes in depressive symptomatology in later life. How much do changes in health status, marital and caregiving status, work and volunteering, and healthrelated behaviors contribute? J Aging Health 19(1):152-177

Cole MG, Dendukuri N (2003) Risk factors for depression among elderly community subjects: a systematic review and meta-analysis. Am J Psychiat 160:1147-1156

Cox-Edwards A, Ureta M (2003) International migration, remittances and schooling: evidence from El Salvador. J Dev Econ 72(2):429-461

Dave D, Rashad I, Spasojevic J (2008) The effects of retirement on physical and mental health outcomes. South Econ J 75(2):497-523

Dooley C (2014) Methodology. In: Nolan A, O'Regan C, Dooley C, et al. (eds) The over 50s in a changing Ireland: economic circumstances, health and well-being. Trinity College Dublin, pp 187-195

Dykstra PA, de Jong Gierveld J (2004) Gender and marital-history differences in emotional and social loneliness among Dutch older adults. Can J Aging 23:141-155

Dykstra PD, van Tilburg TG, de Jong Gierveld J (2005) Changes in older adult loneliness: results from a seven-year longitudinal study. Res Aging 27:725-747

Expert Group on Mental Health Policy (2006) A vision for change: report of the expert group on mental health policy. Stationery Office, Dublin

Fiori KL, Denckla CA (2012) Social support and mental health in middle-aged men and women: a multidimensional approach. J Aging Health 24(3):407-438

Giannelli GC, Mangiavacchi L (2010) Children's schooling and parental migration: empirical evidence on the "left-behind" generation in Albania. Labour 24:76-92

Grigorian DA, Melkonyan TA (2011) Destined to receive: the impact of remittances on household decisions in Armenia. Rev Dev Econ 15(1):139-153

Layard R (2013) Mental health: the new frontier for labour economics. IZA Journal of Labor Policy 2:2

Leavy RL (1983) Social support and psychological disorder: a review. J Community Psychol 11:3-21

Liebler CA, Sandefur GD (2002) Gender differences in the exchange of social support with friends, neighbors, and co-workers at midlife. Soc Sci Res 31:364-391

Lindeboom M, Portrait F, van den Berg GJ (2002) An econometric analysis of the mental-health effects of major events in the life of older individuals. Health Econ 11:505-520

Mandal B, Roe B (2008) Job loss, retirement and the mental health of older Americans. J Men Health Policy:167-176

McKenzie DJ, Hildebrandt N (2005) The effects of migration on child health in Mexico. Economia 6(1):257-289

McKenzie D, Rapoport H (2011) Can migration reduce educational attainment? Evidence from Mexico. J Popul Econ 24:1331-1358

Mincer J (1978) Family migration decisions. J Polit Econ 86(5):749-73

Mu R, de Brauw A (2015) Migration and young child nutrition: evidence from rural China. J Popul Econ 28:631-657 
O'Sullivan V, Nolan B, Barrett A, Dooley C (2014) Income and wealth in The Irish Longitudinal Study on Ageing. Econ Soc Rev 45(3):329-348

Radloff LS (1977) The CES-D scale: a self-report depression scale for research in the general population. Appl Psych Meas 1:385-401

Russell D (1996) The UCLA loneliness scale (version 3): reliability, validity, and factor structure. J Pers Assess 66:20-40

Schoevers RA, Beekman ATF, Deeg DJ, et al. (2000) Risk factors for depression in later life; results of a prospective community based study (AMSTEL). J Affect Disorders 59(2):127-137

Schonlau M (2005) Boosted regression (boosting): an introductory tutorial and a Stata plugin. Stata J 5(3):330-354

Schuster TL, Kessler RC, Aseltine RH (1990) Supportive interactions, negative interactions, and depressed mood. Am J Community Psychol 18(3):423-438

Silverstein M, Cong Z, Shuzhuo L (2006) Intergenerational transfers and living arrangements of older people in rural China: consequences for psychological well-being. J Gerontol B Psychol Sci Soc Sci 61(5):S256-S266

Sonnenberg CM, Beekman ATF, Deeg DJH, van Tilburg W (2000) Sex differences in late-life depression. Acta Psychiatr Scand 101:286-292

Stafford M, McMunn A, Zaninotto P, Nazroo J (2011) Positive and negative exchanges in social relationships as predictors of depression: evidence from the English Longitudinal Study of Aging. J Aging Health 23(4):607-628

Swain SO (1992). In: Nardi P (ed) Men's friendships with women: intimacy, sexual boundaries, and the informant role. SAGE, Newbury Park, CA, pp 153-171

Theeke LA (2009) Predictors of loneliness in U.S. adults over age sixty-five. Arch Psychiat Nurs 23(5):387-396

Tiedt AD (2013) Cross-national comparisons of gender differences in late-life depressive symptoms in Japan and the United States. J Gerontol B Psychol Sci Soc Sci 68(3):443-454

Wooldridge JM (2006) Introductory econometrics: a modern approach. Thomson South-Western 
Reproduced with permission of the copyright owner. Further reproduction prohibited without permission. 